\title{
Biphenyl Modulates the Expression and Function of Respiratory Oxidases in the Polychlorinated-Biphenyls Degrader Pseudomonas pseudoalcaligenes KF707
}

\author{
Federica Sandri ${ }^{1+}$, Stefano Fedi ${ }^{1 \dagger}$, Martina Cappelletti ${ }^{1}$, Francesco M. Calabrese ${ }^{2,3}$, \\ Raymond J. Turner ${ }^{4}$ and Davide Zannoni ${ }^{1 *}$ \\ ${ }^{1}$ Department of Pharmacy and Biotechnology, University of Bologna, Bologna, Italy, ${ }^{2}$ Department of Biosciences, \\ Biotechnology and Pharmacological Sciences, University of Bari "Aldo Moro," Bari, Italy, ${ }^{3}$ Department of Biology, University \\ of Bari "Aldo Moro," Bari, Italy, ${ }^{4}$ Department of Biological Sciences, University of Calgary, Calgary, AB, Canada
}

OPEN ACCESS

Edited by:

Biswarup Mukhopadhyay, Virginia Tech, United States

Reviewed by:

Hiroyuki Arai,

University of Tokyo, Japan Ulrike Kappler,

University of Queensland, Australia

${ }^{*}$ Correspondence:

Davide Zannon

davide.zannoni@unibo.it

${ }^{\dagger}$ These authors have contributed equally to this work.

Specialty section:

This article was submitted to Microbial Physiology and Metabolism, a section of the journal

Frontiers in Microbiology

Received: 03 March 2017 Accepted: 16 June 2017

Published: 30 June 2017

Citation:

Sandri F, Fedi S, Cappelletti M,

Calabrese FM, Turner RJ and Zannoni D (2017) Biphenyl Modulates the Expression and Function of

Respiratory Oxidases in the

Polychlorinated-Biphenyls Degrader Pseudomonas pseudoalcaligenes KF707. Front. Microbiol. 8:1223. doi: 10.3389/fmicb.2017.01223
Pseudomonas pseudoalcaligenes KF707 is a soil bacterium which is known for its capacity to aerobically degrade harmful organic compounds such as polychlorinated biphenyls (PCBs) using biphenyl as co-metabolite. Here we provide the first genetic and functional analysis of the KF707 respiratory terminal oxidases in cells grown with two different carbon sources: glucose and biphenyl. We identified five terminal oxidases in KF707: two c(c)aa $a_{3}$ type oxidases ( $\mathrm{Caa}_{3}$ and $\left.\mathrm{Ccaa}_{3}\right)$, two $\mathrm{cbb}_{3}$ type oxidases ( $\mathrm{Cbb}_{3} 1$ and $\left.\mathrm{Cbb}_{3} 2\right)$, and one bd type cyanide-insensitive quinol oxidase (ClO). While the activity and expression of both $\mathrm{Cbb}_{3} 1$ and $\mathrm{Cbb}_{3} 2$ oxidases was prevalent in glucose grown cells as compared to the other oxidases, the activity and expression of the $\mathrm{Caa}_{3}$ oxidase increased considerably only when biphenyl was used as carbon source in contrast to the $\mathrm{Cbb}_{3} 2$ oxidase which was repressed. Further, the respiratory activity and expression of

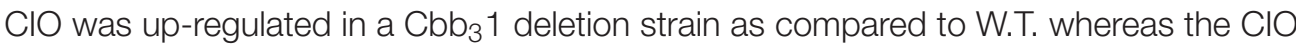
up-regulation was not present in $\mathrm{Cbb}_{3} 2$ and $\mathrm{C}(\mathrm{c}) \mathrm{aa}_{3}$ deletion mutants. These results, together, reveal that both function and expression of $c b b_{3}$ and $c a a_{3}$ type oxidases in KF707 are modulated by biphenyl which is the co-metabolite needed for the activation of the PCBs-degradation pathway.

Keywords: biphenyl growth, gene expression, respiratory activities, terminal oxidases, Pseudomonas pseudoalcaligenes KF707

\section{INTRODUCTION}

The bacterium Pseudomonas pseudoalcaligenes KF707, isolated in the 1980s near a biphenyl (BP) manufacturing plant in Japan (Furukawa and Miyazaki, 1986), is known as one of the most effective aerobic degraders of polychlorinated biphenyls (PCBs) (Fedi et al., 2001). Notably, these harmful and highly hydrophobic organic compounds are not primary substrates for cell growth so that a substrate such as biphenyl is required to support growth and induction of the PCBs degradation pathway 
(Furukawa and Miyazaki, 1986; Furukawa et al., 1993; Fedi et al., 2001). In this way, bacteria such as KF707 that are able to grow on biphenyl have the capacity to co-metabolize various PCBs congeners (Fedi et al., 2001). Despite the fact that most of the biphenyl degradation enzymes required for PCBs degradation are expressed during the aerobic growth of KF707 (Furukawa et al., 1993), no report is available on the functional arrangement of KF707 respiratory chain with biphenyl as carbon source. Indeed, an early biochemical study was published which aimed to define the effect of the toxic oxyanion tellurite on aerobic growth of KF707 in rich-medium (LB-broth) (Di Tomaso et al., 2002). This work suggested the presence in KF707 of a branched respiratory chain leading to two cytochrome (cyt) $c$ oxidases and one cyanide insensitive quinol oxidase (CIO) (Di Tomaso et al., 2002). Since then no other studies on function and composition of the respiratory redox chain of this aerobic PCBs degrader have been published while in the meantime the expression and arrangement of the respiratory chains in species such as Pseudomonas (P.) putida PAK and P. aeruginosa PAO1, were elucidated (Kawakami et al., 2010; Arai, 2011; Sevilla et al., 2013; Arai et al., 2014). In strain PAO1 it was shown that the $a a_{3}$ type oxidase, which plays a major role in aerobic respiration of several bacterial species (Poole and Cook, 2000), is expressed primarily under nutrient-limited conditions and is otherwise a minor player under nutrient-rich growth conditions, e.g., LB-broth (Kawakami et al., 2010). Conversely, two $c b b_{3}$ type oxidases $\left(\mathrm{Cbb}_{3} 1\right.$ and $\left.\mathrm{Cbb}_{3} 2\right)$ and a cyanide insensitive oxidase (CIO) are crucial when oxygen becomes limiting and during growth in biofilms (Comolli and Donohue, 2002, 2004; Alvarez-Ortega and Harwood, 2007; Kawakami et al., 2010). The $\mathrm{Cbb}_{3} 1$ oxidase is expressed constitutively while the $\mathrm{Cbb}_{3} 2$ is induced through oxygen limitation (Comolli and Donohue, 2004; Kawakami et al., 2010). Notably, mutation of the ccol genes coding for the $\mathrm{Cbb}_{3} 1$ oxidase causes up-regulation of the $\mathrm{CIO}$ promoter in P. aeruginosa (Kawakami et al., 2010) indicating that the interactive regulation of the genes for $\mathrm{Cbb}_{3}-1$ and $\mathrm{CIO}$ is mediated by the redox-sensitive transcriptional regulator RoxSR (Bueno et al., 2012).

To fill the molecular and functional gap between our present knowledge of respiration in KF707 and the most investigated Pseudomonas spp., here we provide the first functional analysis of the KF707 respiratory genes (GenBank Acc. no. AP014862; Triscari-Barberi et al., 2012) in relation with two different primary carbon sources for growth such as glucose and biphenyl, while the remaining oxidative growth conditions were kept constant. This is an important aspect as the response of the central carbon catabolism to nutritional compounds is an absolute requirement for effective microbial colonization of a given environment (Rojo, 2010; Shimizu, 2014). Nevertheless, the modulation by the growth carbon source of the oxidative electron transport chain (ETC) that is the machinery which transduces into energy the reducing metabolic power, remains a puzzling issue (Dominguez-Cuevas et al., 2006; Nikel and Chavarria, 2015; Nikel et al., 2016).

Here we show that KF707 contains five different aerobic terminal oxidases: two of $c(c) a a_{3}$ type ( $\mathrm{Caa}_{3}$ and $\mathrm{Ccaa}_{3}$ ), two isoforms of $c b b_{3}$ type $\left(\mathrm{Cbb}_{3} 1\right.$ and $\left.\mathrm{Cbb}_{3} 2\right)$, and one $b d$ type cyanide-insensitive quinol oxidase (CIO). However, while the function and expression of both $\mathrm{Cbb}_{3} 1$ and $\mathrm{Cbb}_{3} 2$ oxidases is prevalent in glucose grown cells as compared to other oxidases, the expression of $\mathrm{Caa}_{3}$ and $\mathrm{Cbb}_{3} 2$ oxidases were 4 -fold increased and 7-fold decreased, respectively, when biphenyl was used as the sole carbon source along with a very low contribution to respiration of CIO. Furthermore, the respiratory activity and expression of $\mathrm{CIO}$ in glucose grown cells were up to 7 times higher in $\mathrm{Cbb}_{3} 1$ deletion mutant as compared to W.T. cells whereas this CIO upregulation was not present in $\mathrm{Cbb}_{3} 2$ and $\mathrm{C}(\mathrm{c}) \mathrm{aa}_{3}$ deletion mutants.

This work not only reveals unexpected features of P. pseudoalcaligenes KF707 respiratory chain such as for example the presence of a $\mathrm{Caa}_{3}$ oxidase induced by growth in biphenyl but it also integrates the functional and genetic data obtained in the past with this PCBs-degrader (Taira et al., 1992; Furukawa et al., 1993; Fujihara et al., 2006; Tremaroli et al., 2007, $2008,2010,2011)$ allowing the establishment of solid molecular basis to better understand the use of toxic aromatics as energy and carbon source.

\section{MATERIALS AND METHODS}

\section{Bacterial Strains and Growth Conditions}

P. pseudoalcaligenes KF707, wild type (W.T.) and mutants, and Escherichia coli strains harboring cloning vectors and recombinant plasmids used in this study are described in Table 1. Luria Bertani medium (LB), $\mathrm{pH}$ 7.2, was routinely used for bacterial growth. Trans-conjugants were selected on $\mathrm{AB}$ defined medium, $\mathrm{pH} 7.2,\left(\mathrm{~K}_{2} \mathrm{HPO}_{4}, 3 \mathrm{~g} \mathrm{~L} \mathrm{~L}^{-1}\right.$; $\mathrm{NaH}_{2} \mathrm{PO}_{4}, 1 \mathrm{~g} \mathrm{~L}^{-1} ; \mathrm{NH}_{4} \mathrm{Cl}, 1 \mathrm{~g} \mathrm{~L}^{-1} ; \mathrm{MgSO}_{4}, 300 \mathrm{mg} \mathrm{L}{ }^{-1}$; $\mathrm{KCl} 150 \mathrm{mg} \mathrm{L}^{-1}, \mathrm{CaCl}_{2}, 10 \mathrm{mg} \mathrm{L}^{-1} ; \mathrm{FeSO}_{4} 7 \mathrm{H}_{2} \mathrm{O} 2.5 \mathrm{mg}$ $\left.\mathrm{L}^{-1}\right)$ with $\mathrm{D}$-glucose $\left(5 \mathrm{~g} \mathrm{~L}^{-1}\right)$ as carbon source. Antibiotics were added to KF707 and E. coli growth medium at the following concentrations: ampicillin (Amp), $50 \mu \mathrm{g} \mathrm{mL} \mathrm{m}^{-1}$, kanamycin $(\mathrm{Km}), 25 \mu \mathrm{g} \mathrm{mL} \mathrm{m}^{-1}$, gentamycin $(\mathrm{Gm}), 10 \mu \mathrm{g}$ $\mathrm{mL}^{-1}$.

Growth curves of KF707 W.T. and mutant strains on different carbon sources (glucose and biphenyl) were conducted in $250 \mathrm{~mL}$ Erlenmeyer flasks containing $50 \mathrm{~mL}$ of mineral salt medium (MSM), pH 7.2, at $30^{\circ} \mathrm{C}$ and $130 \mathrm{rpm}$ (Tremaroli et al., 2010). A single colony of KF707 was first inoculated in $10 \mathrm{~mL}$ of LB medium and grown overnight, cells were centrifuged and washed twice with $0.1 \mathrm{M}$ phosphate buffer $(\mathrm{pH}$ 7.0) then inoculated $(1.0 \% \mathrm{v} / \mathrm{v})$ on MSM medium supplemented with a single carbon source (biphenyl or glucose). Each carbon source was added to the sterile medium in order to have a final carbon concentration of $6 \mathrm{mM}$. Growth curves were performed by monitoring the $\mathrm{OD}_{600}$ level, every $2 \mathrm{~h}$, until the late stationary phase $(24 \mathrm{~h}$ for growth with glucose and $30 \mathrm{~h}$ for growth with biphenyl) was reached. Generation times $(g)$ were calculated during the exponential growth phase. A oneway ANOVA was performed to test the null hypothesis that were no differences in the mean of $g$ of the strains (see Text for details), followed by a two-sample $T$-test within pairs of strains. 
TABLE 1 | List of bacterial strains and plasmids, used in this study.

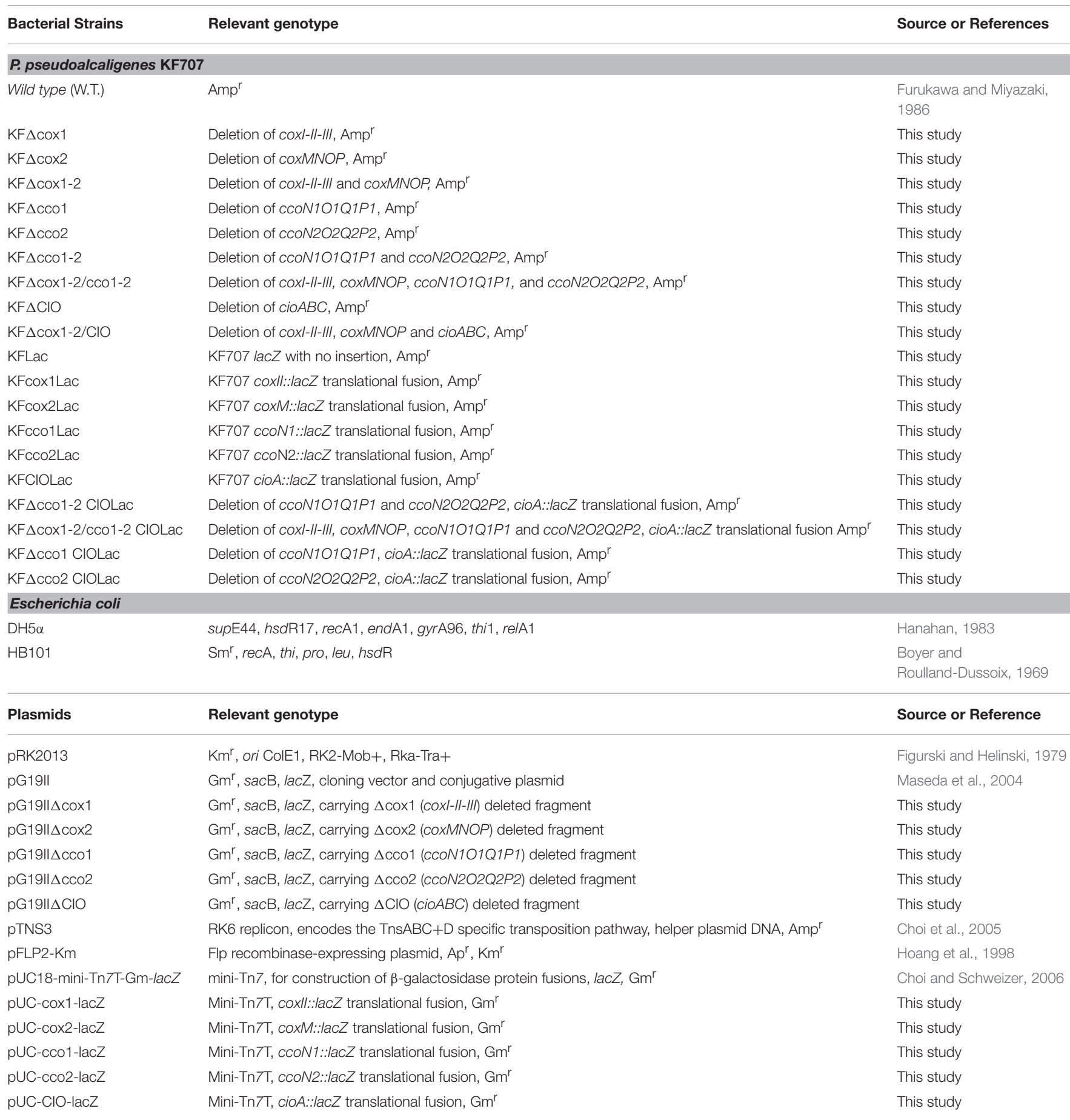

Names of KF707's deletion and translational fusion mutant strains were assigned based on Kawakami et al. (2010).

\section{Construction of KF707 Terminal Cytochrome Oxidase Deleted Mutants}

Nucleotide and amino acid sequences used in this study were based on the complete genome sequence of $P$. pseudolcaligenes KF707 available in GenBank under the accession no. AP014862. Sequence similarity searches were performed using BLAST software (https://blast.ncbi.nlm.nih.gov/Blast.cgi) (Altschul et al., 1990) together with the conserved domain database (https:// www.ncbi.nlm.nih.gov/Structure/cdd/wrpsb.cgi) while multiple sequence alignments were performed with ClustalW software (Thompson et al., 1994). The accession numbers of the genes mentioned in this paper are summarized in Table S2 
of the Supplementary Material or directly reported in the text.

KF707 deleted mutants for single or multiple oxidases (Table 1) were obtained by Gene SOEing PCR technique (Izumi et al., 2007). For the construction of recombinant sequences with deletion in specific genes the primer pairs for the amplification of the upstream flanking region, and the primer pairs for the amplification of the downstream flanking region, were used (Table S1). The outer primers, specifically the forward for the upstream region and the reverse for the downstream one, were designed with specific restriction sites (Table S1). The inner primers, specifically the reverse for the upstream region and the forward for the downstream one, included overlapping sequences in order to join the flanking regions together as described previously (Izumi et al., 2007) (Table S1).

The recombinant sequences with the deletion genes obtained by the SOEing method, were double digested and cloned in specific restriction sites of the conjugative plasmid pG19II in order to construct pG19II $\Delta \operatorname{cox} 1$, pG19II $\Delta \operatorname{cox} 2$, pG19II $\Delta$ cco1, pG19II $\Delta$ cco2, and pG19II $\Delta$ CIO (Table 1) (Maseda et al., 2004). Recombinant plasmids were introduced into chemically competent cells of $E$. coli DH5 $\alpha$ host and transformants were selected for $\mathrm{Gm}$ resistance along with white/blue screening by adding X-gal to agar media at a final concentration of 40 $\mu \mathrm{g} \mathrm{mL}{ }^{-1}$. E. coli $\mathrm{DH} 5 \alpha$, containing each pG19II recombinant plasmid, was used as donor strain and plasmid was transferred by tri-parental conjugation to the recipient KF707 wild type strain by means of the helper strain E. coli HB101 pRK2013. The conjugation included two steps of homologous recombination. The first crossover recombination results in integration of the recombined pG19II plasmid into the genome, transconjugants were selected for their resistance to $\mathrm{Gm}$ and sensitivity to sucrose (Maseda et al., 2004). After the second single crossover recombination, only the cells that had lost pG19II were selected by growth in the presence of $20 \%$ sucrose; their phenotype at the end result was $\mathrm{Gm}$ sensitive and sucrose resistance (Maseda et al., 2004). Deletion mutants were confirmed by PCR and sequencing analysis.

\section{Construction of KF707 lacZ Translational Fusion Mutants}

To evaluate the activity of terminal oxidases in KF707, $\beta$ galactosidase assays were performed by using mutant strains containing translational fusions of the terminal oxidases with lac $Z$ gene. The lacZ-containing strains were constructed by utilizing a Tn7-based method and the translational fusion fragments were inserted into the genome of KF707 at the att Tn7 site located downstream of $g l m S$ (Choi and Schweizer, 2006).

The promoter region, the ATG start codon and the coding region for the first 10 amino-acids, of $\operatorname{coxII}$ ( $\operatorname{cox} 1$ gene clusterKFcox1Lac), coxM ( $\operatorname{cox} 2$ gene cluster-KFcox2Lac), ccoN1 (cco1 gene cluster-KFccolLac), ccoN2 (cco2 gene cluster$\mathrm{KFcco} 2 \mathrm{Lac}$ ), and cioA (cio gene cluster-KFCIOLac) were amplified by PCR, using primers in the Table S1. These fragments were cloned into the pUC-miniTn7-Gm-lacZ vector and the resultant plasmid were electroporated, with the helper plasmid
pTNS3 (Choi et al., 2005), into KF707. Then the mutant strains were obtained with the method described by Kawakami et al. (2010).

Finally, $\beta$-galactosidase assays were performed at $30^{\circ} \mathrm{C}$ in MSM minimal medium with glucose or biphenyl as single carbon source, at two different phases of growth (exponential phase$\mathrm{OD}_{600 \mathrm{~nm}} 0.3-0.5$ and stationary phase-OD $600 \mathrm{~nm}$ 0.7-0.9) using a standard protocol (Sambrook et al., 1989); each experiment was repeated at least six times.

\section{Enzymatic Activities with NADI assay}

To observe the cytochrome $c$ oxidases activity in intact cells of W.T. and mutant strains, a NADI assay was carried out (Marrs and Gest, 1973). KF707 strains were grown until the stationary phase $\left(\mathrm{OD}_{600 \mathrm{~nm}}\right.$ 0.7-0.9), in minimal medium (MSM) with glucose or biphenyl as single carbon source. $1 \mathrm{~mL}$ of culture was collected, centrifuged and washed twice with $1 \mathrm{ml}$ of Tris$\mathrm{HCl} 10 \mathrm{mM}$ (pH 7.5). Subsequently, $100 \mu \mathrm{L}$ of a 1:1 mixture

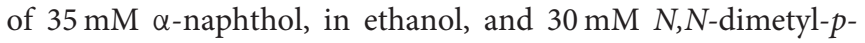
phenylenediamine monohydrochloride (DMPD), in water, was added to the cells. The reaction mixture was incubated at room temperature for a few seconds and the color change was observed within $1 \mathrm{~min}$.

\section{Preparation of Membrane Fragments}

For the preparation of membrane fragments, cells were grown aerobically until the stationary phase $\left(\mathrm{OD}_{600 \mathrm{~nm}} 0.7-0.9\right)$ in $3 \mathrm{~L}$ Erlenmeyer flasks containing $1 \mathrm{~L}$ of mineral salt medium (MSM), $\mathrm{pH} 7.2$ at $30^{\circ} \mathrm{C}$ and $130 \mathrm{rpm}$, with $6 \mathrm{mM}$ of glucose or biphenyl as single carbon source. Growths were stopped after 16 and/or $30 \mathrm{~h}$ for glucose or biphenyl medium, respectively. Cells were washed twice with $0.1 \mathrm{M}$ phosphate buffer to reach about $1.6 \mathrm{~g}$ of wet weight cells. Membrane fragments for respiratory activities and spectroscopic analysis were obtained using French pressure cell and ultracentrifugation, in $50 \mathrm{mM}$ MOPSO buffer ( $\mathrm{pH}$ 7.2) containing $5 \mathrm{mM} \mathrm{MgCl} 2$ (Di Tomaso et al., 2002). Membranes were suspended at a known protein concentration $(5-10 \mathrm{mg}$ $\mathrm{mL}^{-1}$ ) in the same buffer and used immediately for analysis. Experiments were conducted in membranes of W.T. and mutant cells from at least two/three independent cell preparations (see Figure and Table legends).

\section{Spectroscopic Analyses, Respiratory Activities, and Protein Determination}

The amounts of cytochromes in membrane fragments were estimated by recording reduced (with $0.5 \mathrm{mM} \mathrm{NADH}$ plus $5 \mathrm{mM} \mathrm{KCN}$ and/or a few crystals of sodium dithionite)-minusoxidized [with a few crystal(s) of potassium ferricyanide] optical difference spectra at room temperature with a Jasco 7800 spectrophotometer. Absorption coefficients $\epsilon_{603}-630$ of $11.6 \mathrm{mM}^{-1} \mathrm{~cm}^{-1}, \epsilon_{561-575}$ of $22 \mathrm{mM}^{-1} \mathrm{~cm}^{-1}$, and $\epsilon_{551-542}$ of $19.1 \mathrm{mM}^{-1} \mathrm{~cm}^{-1}$ were used to determine the amounts of $a-, b$-, and $c$-type cytochromes, respectively (Kishikawa et al., 2010).

Respiratory activities in membrane fragments isolated from KF707 W.T. and deletion mutant strains, were determined by monitoring the oxygen consumption with a Clark-type oxygen electrode YSI 53 (Yellow Springs Instruments) as described 
previously (Daldal et al., 2001). Activities in the presence or absence of specific inhibitors (see Text for details) were measured within a few hours after the end of the membrane isolation procedure. The inhibitory concentration $\mathrm{IC}_{50}$ was the concentration of an inhibitor required to inhibit $50 \%$ of the target enzymatic activity.

Protein content of samples was determined using the Lowry assay with bovine serum albumin (BSA) as a standard (Lowry et al., 1951).

\section{RESULTS}

\section{Putative Genes for Terminal Oxidases The $\mathrm{aa}_{3}$ Type Cytochrome Oxidases of KF707}

The analysis of the $P$. pseudoalcaligenes KF707 complete genome shows the presence of two gene clusters for two different cox oxidases of $a a_{3}$ type whose subunits are predicted to contain $c$ type hemes: $\mathrm{caa}_{3}$ and $c c a a_{3}$ type oxidases. The $c a a_{3}$ type oxidase is encoded by coxI-II-III (BAU71738-71737-71740) gene cluster (Figure 1; Table S2). The three subunits, which are annotated as part of $a a_{3}$ type cytochrome $c$ oxidase in the KF707 genome, have sequences with high similarity ( 90\%) to CoxB, CoxA, and CoxC of P. aeruginosa (Stover et al., 2000). Similarly to $P$. aeruginosa, subunit I ( $58.8 \mathrm{KDa})$ of $\mathrm{KF} 707$ is predicted to carry a low spin $a$-type heme and one heme $a_{3}-\mathrm{Cu}_{\mathrm{B}}$ binuclear catalytic center. The predicted subunit II ( $42 \mathrm{KDa})$ consists of a membrane anchored cupredoxin domain, containing the electron-accepting homo-binuclear copper-center, $\mathrm{Cu}_{\mathrm{A}}$, with a carboxy-terminal fusion to a cytochrome $c$ domain (Lyons et al., 2012). The presence of a $c$-type heme in the $a a_{3}$ type oxidase of KF707 was suggested by an alignment analysis (Supplementary MaterialAlignment 1) which showed, in the C-terminal region, the typical amino-acids residues $(\mathrm{Cxx}-\mathrm{CH})$, that coordinate the heme $c$ in Thermus thermophilus and Rhodothermus marinus $\mathrm{caa}_{3}$ oxidases (Lyons et al., 2012); these characteristic residues are absent from Rhodobacter sphaeroides and Paracoccus denitrificans $a a_{3}$ oxidases while the CoxII amino acid sequence of KF707 has 81\% similarity with the CoxB of $P$. aeruginosa PAO1.

In KF707 an additional $c c a a_{3}$ type oxidase is predicted to be encoded by the gene cluster coxMNOP (BAU7442874432) (Figure 1; Table S2). Sequence analyses showed that this alternative complex is characterized by the organization which is typical of $a a_{3}$ type cytochrome oxidases present in Sinorhizobium meliloti 1021, Cupriavidus metallidurans CH34, Mesorhizobium sp., and Polaromonas (Preisig et al., 1996b). Previous studies have shown that the coxMNOP gene cluster encodes a complex with homology to $\mathrm{Cu}$-containing cyt $c$ oxidase; indeed it was observed that the subunit I ( $66 \mathrm{KDa})$, encoded by $\operatorname{cox} N$, was very similar to CoxA of $P$. aeruginosa (Bott et al., 1992) and to CoxI of KF707's $\mathrm{Caa}_{3}$. The alignment suggested that CoxM (52 $\mathrm{KDa}$ ) of KF707 showed, in the C-terminal portion, two $c$-type hemes (Supplementary Material-Alignment 2) and therefore this oxidase is a $\mathrm{ccaa}_{3}$ cytochrome oxidase; in this case, in the $\mathrm{C}$ terminal portion, there is a repetition of the residues $(\mathrm{Cxx}-\mathrm{CH})$ that coordinate the $c$-type hemes. These enzymes are not common, but they have also been found in bacteria such as Desulfovibrio vulgaris (Lobo et al., 2008) and Shewanella oneidensis MR-1 (Le Laz et al., 2014). In KF707 CoxP and CoxO amino acid sequences are homologs to subunit III of the $a a_{3}$ complex.

\section{The $\mathrm{cbb}_{3}$ Type Oxidases of KF707}

Two complete sets of genes encoding cyt $c$ oxidases of $c b b_{3}$ type $\left(\mathrm{Cbb}_{3} 1\right.$ and $\left.\mathrm{Cbb}_{3} 2\right)$ are present in KF707 (Figure 1; Table S2). These genes, tandemly clustered in the genome of KF707, are situated in the ccoN1O1Q1P1 (BAU73552-73555) and ccoN2O2Q2P2 (BAU73556-73559) clusters as previously shown in $P$. aeruginosa strains PAO1 and PA7, P. putida KT2440, and $P$. fluorescens (Stover et al., 2000). Similarly to orthodox $c b b_{3}$ type oxidases, the catalytic subunit I ( $\sim 50 \mathrm{KDa})$ of KF707 encoded by $c c o N$ gene is expected to comprise 12 transmembrane helices and to contain, in addition to the low spin $b$-type heme, a binuclear center formed by high spin $b_{3}$ heme and $\mathrm{Cu}_{\mathrm{B}}$. In general, the two trans-membrane cytochrome $c$ subunits with $c$-type monoheme and diheme groups are encoded by the genes $c c o O(\sim 22 \mathrm{KDa})$ and $\operatorname{ccoP}(\sim 40 \mathrm{KDa})$ respectively, while CcoQ $(\sim 7 \mathrm{KDa})$ are necessary for the stability of the complex. These oxidases utilize cytochrome $c$ as an electron donor and they lack a $\mathrm{Cu}_{\mathrm{A}}$ site.

In general, the $c c o N O Q P$ operons encoding $c b b_{3}$ oxidase subunits are found in association with the ccoGHIS (BAU7354873551) gene cluster which is located in the downstream region and whose expression is required for the maturation and assembly of a functional $c b b_{3}$ oxidase and this type of gene organization is also present in KF707 (Figure 1; Table S2) (Preisig et al., 1996a; Koch et al., 2000; Pitcher and Watmough, 2004). Homology searching of both ccoNOQP and ccoGHIS, showed the same gene arrangement among $P$. aeruginosa strains PAO1 and PA7, $P$. putida KT2440, and $P$. entomophila L48 while $P$. aeruginosa strains UCBPP-PA14 and LESB58, $P$. stutzeri A1501, and P. mendocina YMP showed similar features except that some of them lack one copy of the ccoQ gene.

\section{The Cyanide-Insensitive Oxidase of KF707}

In the past, an oxidase activity insensitive to cyanide (CIO), which accounts for $\sim 20 \%$ of the total NADH-dependent respiration of LB-grown KF707 cells, has been reported (Di Tomaso et al., 2002). Here we show that KF707 genome contains two genes coding for two subunits which are highly similar to those of cytochrome $b d$ type quinol oxidases of Pseudomonas fulva $12-X$ and $P$. mendocina (Figure 1; Table S2). In E. coli and other Gram negative bacteria, the cyt $b d$-I complex consists of two subunits named CydA (subunit I) and CydB (subunit II), while in Pseudomonas spp. it is encoded by the $c i o A$ and $c i o B$ genes, respectively (Cunningham et al., 1997). In KF707, genes cioA (BAU72498) and cioB (BAU72499) code for two orthodox subunits in addition to a third accessory subunit encoded by cioC (BAU72500).

The $b d$ oxidase functions as a quinol oxidase with a relatively low sensitivity to cyanide and it shows often high affinity for oxygen (D’mello et al., 1996). CIO contains low-spin heme $b_{558}$, high spin heme $b_{595}$ and heme $d$ (Jünemann, 1997; Siletsky et al., 2016). It should be noted that although both the $\operatorname{cio} A$ and $\operatorname{cio} B$ genes are highly similar to the $c y d A B$ genes encoding a $b d$-type oxidase, the CIO from KF707 lacks the spectral features of hemes 


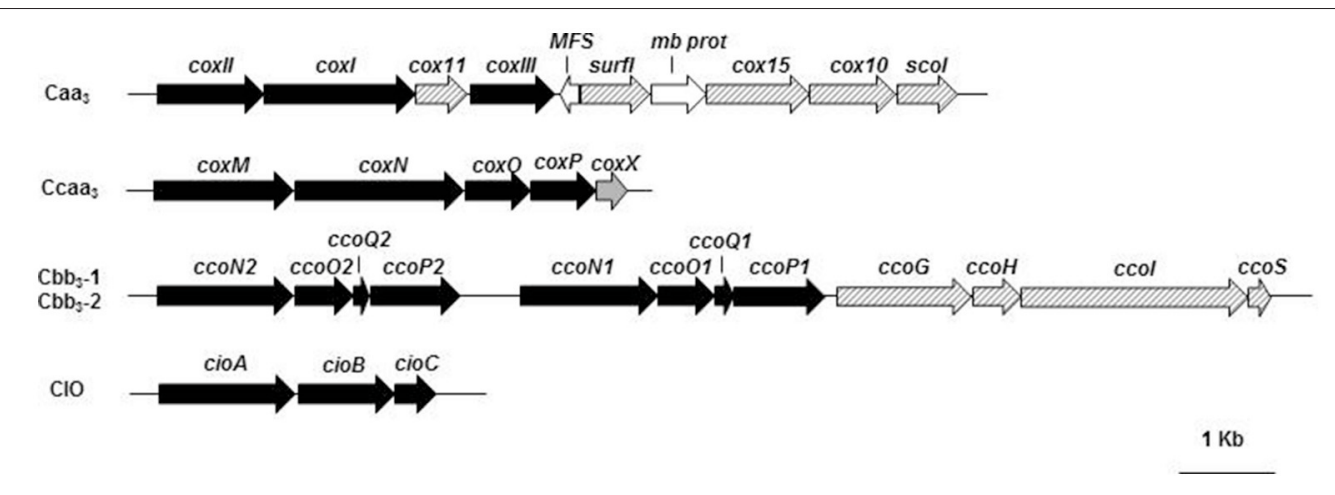

FIGURE 1 | Organization of the terminal oxidase gene clusters in KF707: cox, encoding for cytochrome $c$ oxidases of caa 3 type (coxI-II-III) and ccaa 3 type (coxMNOP); $c c 0$, encoding for gene products involved in the synthesis and assembly of two cytochrome $c$ oxidases of $c b b_{3}$ type (ccoN1O1Q1P1 and ccoN2O2Q2P2); cio, gene cluster for the quinol oxidase $\mathrm{CIO}(\operatorname{ciO} A B C)$. Genes (listed in Table S2) are represented by arrows and by different colors or stripes: black, functional genes; dashed stripes, genes for cytochrome biogenesis; gray, cytochrome $c$ oxidase accessory membrane protein (CoxX); white, genes supposedly not directly related with the gene clusters under analysis. Full names and abbreviations used: MFS, Major Facilitator Superfamily permease; mb prot, membrane protein.

$b_{595}$ and heme $d$ (Matsushita et al., 1983; Di Tomaso et al., 2002) (not shown).

\section{Expression of Membrane Bound Oxidases}

Early biochemical results have shown that membranes isolated from KF707 cells grown in LB-growth medium do not contain significant amounts of $a a_{3}$ type hemes (Di Tomaso et al., 2002). However, since KF707 is capable to aerobically degrade PCBs in the presence of biphenyl as co-metabolite (Abramowicz, 1990) we thought to determine the expression of the entire set of the putative genes for terminal oxidases in cells grown in biphenyl as compared to cells grown on a defined carbon source such as glucose.

The expression pattern in response to the carbon source was determined using lac $Z$ translational fusions that monitor the promoter activities at the translational level. Figure 2 shows the $\beta$-galactosidase activity of each translational fusion when KF707 cells were cultured in glucose and biphenyl medium and harvested at the same cell density in their exponential and stationary growth phases.

The ccol promoter for the $\mathrm{Cbb}_{3} 1$ exhibited similar basic level of expression in both exponential and stationary phases in cells grown with glucose (Figure 2A). Using the same carbon source, the $c c 02$ promoter for the $\mathrm{Cbb}_{3} 2$ showed a high activity in both exponential and stationary phases of growth. In contrast to $c c 02$, the cox 1 promoter for the $\mathrm{Caa}_{3}$ oxidase had a low activity in cells harvested at their exponential growth phase while an activity similar to that of the $c c 01$ promoter was seen in the stationary growth phase. The cox 2 promoter for the $\mathrm{Ccaa}_{3}$ and the cio promoter for the CIO oxidase showed very low activities in both exponential and/or stationary grown cells.

In cells grown with biphenyl (Figure 2B) the ccol promoter exhibited similar levels of expression in both exponential and stationary growth phases. In contrast to $c c 01$, the $c c 02$ promoter showed a high expression level in the exponential phase while cco 2 expression was very low in the stationary phase of growth. Interestingly, the drop of $c c 02$ expression in stationary phase was matched with a drastic increase of cox 1 expression which was 4and 10-times higher than that seen in the exponential growth phase on biphenyl and glucose, respectively. Similarly to cells grown in glucose, the cox 2 and the cio promoters of cells grown in biphenyl showed very low expression values in both exponential and stationary growth phases.

\section{Growth Profiles and NADI Assay}

KF707 W.T. and seven terminal oxidase mutant strains, namely: KF $\Delta \operatorname{cox} 1-2$ ( $\mathrm{Caa}_{3}$ and $\mathrm{Ccaa}_{3}$ minus), KF $\Delta \mathrm{ccol}-2\left(\mathrm{Cbb}_{3} 1\right.$ and $\mathrm{Cbb}_{3} 2$ minus), KF $\Delta$ cox 1-2/ccol-2 (Cbb $1, \mathrm{Cbb}_{3} 2, \mathrm{Caa}_{3}$, and $\mathrm{Ccaa}_{3}$ minus), $\mathrm{KF} \Delta \mathrm{CIO}$ (CIO minus), KF $\Delta \operatorname{cox} 1-2 / \mathrm{CIO}\left(\mathrm{Caa}_{3}\right.$, $\mathrm{Ccaa}_{3}$, and $\mathrm{CIO}$ minus), $\mathrm{KF} \Delta \mathrm{cco} 1$ ( $\mathrm{Cbb}_{3} 1$ minus), and $\mathrm{KF} \Delta \mathrm{cco} 2$ ( $\mathrm{Cbb}_{3} 2$ minus), were tested for their capacity to grow aerobically with glucose or biphenyl as sole carbon source. As shown in Figure 3, the KF $\Delta$ cco1-2 and KF $\Delta$ cox1-2/cco1-2 mutant strains were clearly impaired in their aerobic growth profiles and generation times $(g)$ in glucose $(g=76 \pm 1.5$ and $88 \pm 1.5 \mathrm{~min}$, respectively; $p \leq 0.05)$ as compared to W.T. ( $g=63 \pm 0.8 \mathrm{~min}$; $p \leq 0.05)$. Similarly, KF $\Delta$ ccol-2 and KF $\Delta$ cox1-2/cco1-2 mutant strains were shown to grow slowly in biphenyl $(g=140 \pm 21$ and $147 \pm 26 \mathrm{~min}$, respectively; $p \leq 0.05$ ) as compared to W.T. $(g=97 \pm 8.5 \mathrm{~min} ; p \leq 0.05)$. The results also indicated that the $\mathrm{KF} \Delta \operatorname{cox} 1-2$ and $\mathrm{KF} \Delta \mathrm{CIO}$ mutant growth curves were similar to KF707 W.T. growth curve regardless of the carbon source used for growth although a slight but significant increase of the generation time was seen in KF $\triangle \mathrm{CIO}$ cells grown in glucose and biphenyl $(g=75 \pm 1.4$ and $113 \pm 1.5 \mathrm{~min}$, respectively; $p$ $\leq 0.05$ ). The specific contribution of $\mathrm{Cbb}_{3} 1$ and $\mathrm{Cbb}_{3} 2$ to cell growth was also examined (Figure S1). The growth curves show that the lack of the $\mathrm{Cbb}_{3} 1$ oxidase impaired the growth rate in both glucose $(g=85 \pm 0.4 \mathrm{~min} ; p \leq 0.05)$ and biphenyl $(g=$ $151 \pm 1.7 \mathrm{~min} ; p \leq 0.05)$ while the lack of $\mathrm{Cbb}_{3} 2$ oxidase did not significantly affect the growth with both carbon sources $(g=$ $75 \pm 5 \mathrm{~min}$ and $110 \pm 4.4$, respectively). These results, taken together, indicate that the KF707 optimal growth rates in glucose or biphenyl depend on the simultaneous presence of both $c b b_{3}$ 


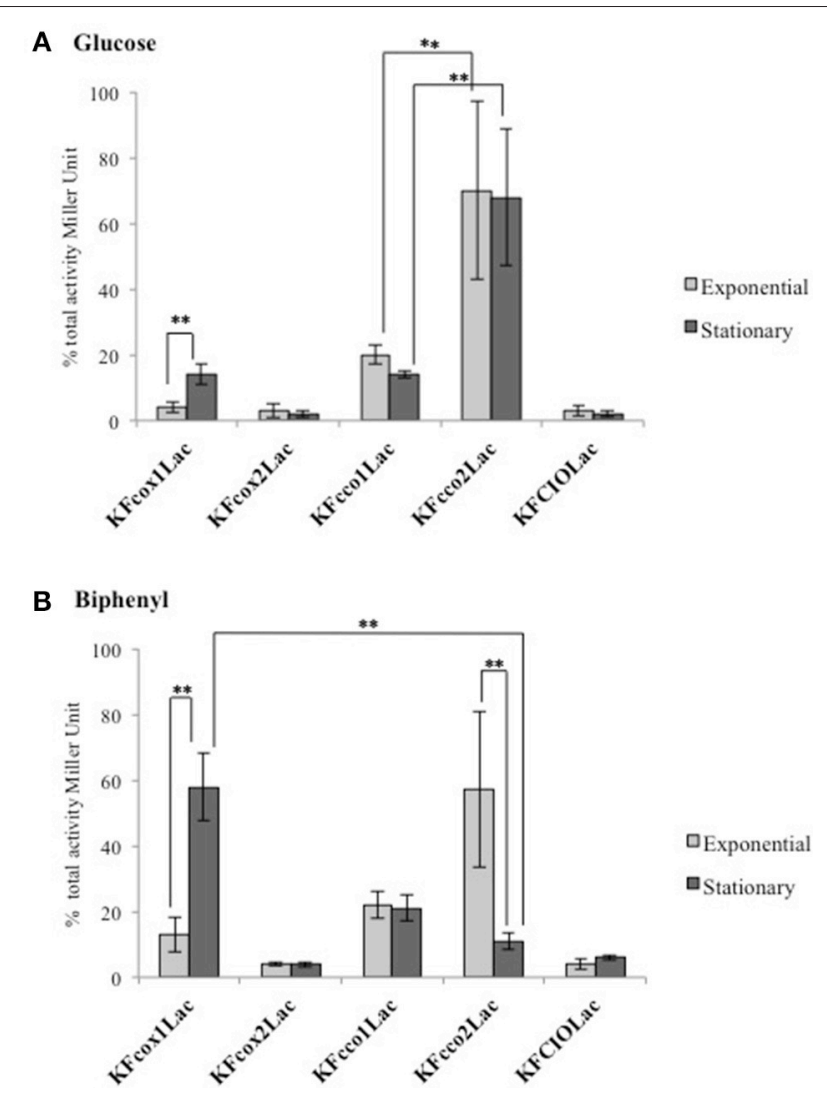

FIGURE 2 | $\beta$-Galactosidase activities measured in cell extracts derived from the KF707 translational fusion mutant strains (Table 1), grown aerobically in MSM medium with glucose (A) and biphenyl (B) as sole carbon source. The assays were performed (at least six times) at two different stages of growth (exponential phase $\mathrm{OD}_{600} \mathrm{~nm} 0.3-0.5$ and stationary phase $\mathrm{OD}_{600} \mathrm{~nm}$ $0.7-0.9)$ and the activities are presented as percentage of total activity. Error bars indicate standard deviation of the means. Asterisks indicate that mean values are significantly different according to one-way ANOVA and verified by a two samples $T$-test within pairs of strains $\left({ }^{\star \star} p<0.01\right)$.

type oxidases along with that of the CIO oxidase. This conclusion is also supported by evidence that despite numerous efforts, it was not possible to obtain a triple oxidase mutant lacking the $\mathrm{CIO}$, $\mathrm{Cbb}_{3} 1$, and $\mathrm{Cbb}_{3} 2$ oxidases, so to suggest that this triple mutant was not viable under the tested aerobic growth conditions.

In addition to growth curves, KF707 W.T. and deletion mutant phenotypes were tested through the use of the NADI assay (Figure S2). This assay aims to visualize the cytochrome $c$ oxidase respiration following the time-course oxidation of the artificial electron donor N,N,dimethyl-pphenylenediamine (DMPD) which appears colorless in its reduced state or blue when it is oxidized to indophenol. With cells grown on glucose the assay was negative only in the case of KF $\Delta$ ccol-2 and KF $\Delta \operatorname{cox} 1-2 /$ ccol-2 mutants, suggesting a negligible activity of $c(c) a a_{3}$ type oxidases. On the contrary, in cells grown on biphenyl the assay was negative only in the case of KF $\Delta \operatorname{cox} 1-2 /$ ccol-2, suggesting a functional role of the $\mathrm{Caa}_{3}$ type oxidase with biphenyl as the carbon source.

\section{Spectroscopic Analysis and Respiratory Activities}

Table 2 and Figure S3 summarize the heme-spectroscopic features of membranes isolated from cells grown in glucose as compared to those from cells grown in biphenyl and harvested at their stationary phase of growth. The spectroscopic evaluation of membranes from glucose grown cells showed that the $\alpha$ band attributable to $a a_{3}$ type hemes is barely detectable at 600-605 nm. Conversely an evident peak at $600-605 \mathrm{~nm}$ which is attributable to $a a_{3}$ type heme (Table 2) was seen in KF707 membranes from cells grown on biphenyl (Figure S3). This observation is therefore in line with the gene expression values reported in Figure 2B showing that the $\operatorname{cox} 1$ promoter activity for the $\mathrm{Caa}_{3}$ oxidase is 4-times enhanced in KF707 biphenyl grown cells harvested in their stationary phase. The spectroscopic results of Table 2 also indicate that the protein subunits encoded by the gene clusters cox123, coxMNOP, ccoN1O1Q1P1, and ccoN2O2Q2P2 (Table S2) all contain considerable amounts of $c$-type hemes as predicted by BLASTP search. Indeed, the amount of $c$-type heme as detected at 551-542 nm, decreased in KF $\Delta \operatorname{cox} 1-2$ and/or KF $\Delta$ cco1-2 mutants and even more drastically in KF $\Delta$ cox 1-2/cco1-2 mutant cells (Figure S3).

Oxidases of $a a_{3}$ and $c b b_{3}$ heme type are thought to function as cytochrome $c$ oxidases whereas $\mathrm{CIO}$ was characterized as a quinol oxidase (Cramer and Knaff, 1990). In the past it was shown that both $c b b_{3}$ and $a a_{3}$ type oxidases in $R$. sphaeroides membranes were inhibited by cyanide $\left(\mathrm{CN}^{-}\right)$and azide $\left(\mathrm{N}_{3}^{-}\right)$anions (Daldal et al., 2001). However, while $50 \mu \mathrm{M} \mathrm{CN}^{-}$fully inhibited both the $c b b_{3}$ and $a a_{3}$ type cytochrome $c$ oxidase activities, $50 \mu \mathrm{M}$ $\mathrm{N}_{3}^{-}$only inhibited the $c b b_{3}$ dependent activities. Thus, in the presence of $50 \mu \mathrm{M}$ cyanide or azide it was possible to determine the contribution of $a a_{3}$ type and/or $c b b_{3}$ type oxidases to the total respiratory activity catalyzed by cytochrome $c$ oxidases (Daldal et al., 2001). Here, the same inhibitor concentration was used to estimate the activities of $\mathrm{KF} 707 \mathrm{Cbb}_{3}$ and $\mathrm{C}(\mathrm{c}) \mathrm{aa}_{3}$ oxidases in the presence or absence of cyanide and azide in membrane obtained from W.T. and mutant cells grown with glucose and biphenyl (Tables 3, 4).

Table 3 shows that with $\mathrm{NADH}$ as an electron donor, the total oxygen consumption by KF707 W.T. membranes from cells grown in glucose (hereafter named $\mathrm{Gcm}$ ) was $66 \%$ inhibited by $50 \mu \mathrm{M}$ azide (contribution of $c b b_{3}$ oxidases) while only a further $17 \%$ was inhibited by $50 \mu \mathrm{M}$ cyanide [contribution of C(c) $\mathrm{aa}_{3}$ oxidases]. The NADH oxidation when measured in membranes from biphenyl grown cells (hereafter named Bpm) (Table 4), was $42 \%$ inhibited by $50 \mu \mathrm{M}$ azide while a further $52 \%$ of the total respiration was sensitive to $50 \mu \mathrm{M}$ cyanide. Apparently, the \% contribution to the $\mathrm{NADH}$ respiration of $\mathrm{C}(\mathrm{c}) \mathrm{aa}_{3}$ oxidases that are resistant to $50 \mu \mathrm{M}$ azide but sensitive to $50 \mu \mathrm{M}$ cyanide, was 3 -fold higher in Bpm (52\%) than in Gcm (17\%). In line with this, the ascorbate/TMPD oxidase activity which indicates the overall oxygen consumption catalyzed by cytochrome $c$ oxidases, was 80 and $47 \%$ repressed by azide in $\mathrm{Gcm}$ and Bpm, respectively, confirming the main role of $c b b_{3}$ type oxidases in $\mathrm{Gcm}$ but not in Bpm. Results in W.T. membranes were confirmed by activities determined in membranes from oxidase mutant cells, with some additional finding, namely: the lack of both $\mathrm{Cbb}_{3} 1$ 
and $\mathrm{Cbb}_{3} 2$ oxidases (KF $\Delta$ ccol-2 mutant) resulted into a strong activation of $\mathrm{CIO}$ dependent activity in $\mathrm{Gcm}$ (72\% resistant to $\mathrm{CN}^{-}$). Further, the CIO activation resulting from the lack of $c b b_{3}$ oxidases was less evident in Bpm (30\% resistant to $\left.\mathrm{CN}^{-}\right)$in which $83 \%$ of the NADH activity was insensitive to azide confirming the main functional role of $\mathrm{caa}_{3}$ type oxidase using biphenyl carbon source (see also Figure 2). Accordingly, in Bpm-KF $\Delta$ cco1-2 the ascorbate/TMPD oxidation was only $8 \%$ inhibited by azide while 95\% was sensitive to cyanide (see also Figure S2, NADI assay). These data, taken together, allowed us to determine in $\mathrm{Gcm}$ $\mathrm{KF} \Delta$ cox1-2 and Bpm-KF $\Delta$ ccol-2 the $\mathrm{IC}_{50}$ for cyanide of $\mathrm{Cbb}_{3}$ and $C(c) a_{3}$ oxidase activities which were in the order of $4.10^{-7}$ $\mathrm{M} \mathrm{CN}^{-}$and $5.10^{-6} \mathrm{M} \mathrm{CN}^{-}$, respectively (Materials and Methods and Figure S4).

As expected by the preceding results, both activation and functional role of $\mathrm{CIO}$ in supporting NADH dependent respiration in $\mathrm{Gcm}$ was also seen in the quadruple oxidase mutant KF $\Delta \operatorname{cox} 1-2 / \operatorname{cco} 1-2$ whose respiratory activity was $100 \%$ insensitive to $50 \mu \mathrm{M}$ cyanide; further, the latter oxidative activity was catalyzed by $\mathrm{CIO}$ with a rate similar to that performed by W.T. membranes in the absence of inhibitors. Bpm-KF $\Delta$ cox12/cco1-2 was therefore used to determine the $\mathrm{IC}_{50}$ for cyanide of $\mathrm{CIO}$ to be close to $1 \mathrm{mM} \mathrm{CN}^{-}$(Figure S4).

To better understand the lack of which of the two $\mathrm{Cbb}_{3}$ oxidases determines an activation of the CIO oxidase activity, and the contribution of each $\mathrm{Cbb}_{3}$ oxidase to the total respiration, the oxygen consumptions in membranes from KF $\Delta \mathrm{ccol}\left(\mathrm{Cbb}_{3} 1\right.$ minus) and/or $\mathrm{KF} \Delta \mathrm{cco} 2$ ( $\mathrm{Cbb}_{3} 2$ minus) mutant cells grown in glucose or biphenyl, were determined. Results in Table $\mathbf{3}$ (bottom lines) show that in glucose grown cells the CIO catalyses $56 \%$ of the total respiration of KF $\Delta$ ccol, being 3-4 times higher than the corresponding activity measured in KF $\Delta$ cco 2 and W.T. membranes, with a parallel minor role $(16 \%)$ of the $\mathrm{Cbb}_{3} 2$ oxidase. Differently, in KF $\Delta \mathrm{cco} 2$ membranes the $\mathrm{Cbb}_{3} 1$ oxidase catalyses $65 \%$ of the total respiration compensating the low CIO activity. Accordingly, the $\beta$-galactosidase assays performed in $\mathrm{KF} \Delta \mathrm{cco} 1 \mathrm{CIOLac}$ and $\mathrm{KF} \Delta \mathrm{cco} 2 \mathrm{CIOLac}$ cell extracts indicated that the expression of $\mathrm{CIO}$ in $\mathrm{KF} \Delta \mathrm{ccol}$ increases 4 times as compared to that of KF $\Delta \mathrm{cco} 2$ (Figure S5). Interestingly, results in Table 4 (bottom lines) show that in biphenyl grown cells the $\mathrm{CIO}$ catalyses $33 \%$ of the total $\mathrm{CN}^{-}$resistant $\mathrm{NADH}$ respiration of $\mathrm{KF} \Delta \mathrm{cco} 1$ with a parallel minor role of the $\mathrm{Cbb}_{3} 2$ oxidase (13\%, see also Figure S5) and a prevalent contribution of the $\mathrm{Caa}_{3}$ oxidase $(54 \%)$ to respiration. Notably, in $\mathrm{KF} \Delta \mathrm{cco} 2$ the CIO activity decreased to $13 \%$ of the total NADH oxidation with a parallel increase of the contribution to respiration of $\mathrm{Cbb}_{3} 1$ $(43 \%)$ and $\mathrm{Caa}_{3}(43 \%)$ oxidases.

One consideration arising from the results of Tables 3, 4 concerns the low values obtained from measurements of cytochrome oxidase activities using horse-heart cytochrome $c$ (HHCyt $c$ ) as electron donor. This activity, in either $\mathrm{Gcm}$ or Bpm was $~ 5-6$ times lower than that measured with TMPD as electron donor suggesting the low capacity of soluble HHCyt $c$ to reduce KF707 respiratory oxidases which are featured by $c$-type hemes as catalytic subunits. This finding contrasts with the capacity of HHCyt $c$ to replace the soluble mono-heme cyt $c_{2}$ which is the physiological electron donor to either $a a_{3}$ or $c b b_{3}$ type oxidases in
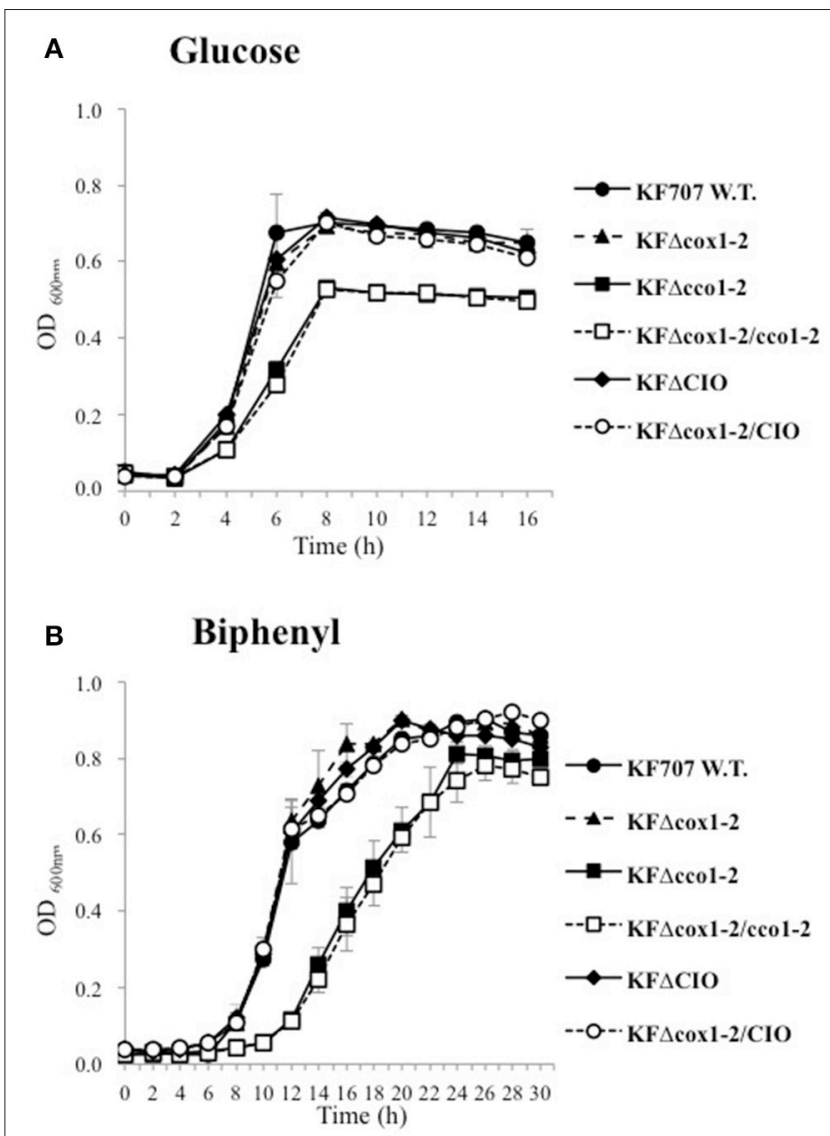

FIGURE 3 | Growth curves of KF707 W.T. and deletion mutant strains (Table 1). Strains were grown in $50 \mathrm{~mL}$ of MSM medium in $250 \mathrm{~mL}$ flasks shaken at 130 r.p.m, with $6 \mathrm{mM}$ of glucose (A) or biphenyl (B). The optical densities were observed at $600 \mathrm{~nm}$ every $2 \mathrm{~h}$. Growths were stopped at late-stationary phase, after 16 and $30 \mathrm{~h}$, respectively for medium containing glucose or biphenyl.

R. sphaeroides (Daldal et al., 2001). Conversely, our observation in KF707 is in line with an early report in which it was shown that HHCyt $c$ was a poor substrate for the $c b b_{3}$ type oxidase activity of $V$. cholera. In this latter species, the rate of oxygen reduction with HHCyt $c$ was several fold lower than with the soluble di-heme cyt $c_{4}$ which was identified as the physiological electron donor to the $\mathrm{Cbb}_{3}$ oxidase (Chang et al., 2010) (see Discussion).

\section{DISCUSSION AND CONCLUSIONS}

\section{The Branched Respiratory Chain of P. pseudoalcaligenes KF707 Terminal Cytochrome Oxidases}

In the past, the heme-copper oxygen $(\mathrm{HCO})$ reductases were classified into three families: (1) type A or mitochondrial like oxidases of $a a_{3}$ type; (2) type B or ba type oxidases; and (3) type $\mathrm{C}$ or $c b b_{3}$ type oxidases which are only detected in bacteria (Sousa et al., 2012). Additionally, cyt $b d$ type oxidases which are phylogenetically unrelated to $\mathrm{HCO}$, represent a second major 
TABLE 2 | Heme amounts of a-, b-, and c-type in membranes isolated from KF707 W.T. and oxidase mutant cells grown with glucose and/or biphenyl as unique carbon source.

\begin{tabular}{|c|c|c|c|c|}
\hline Carbon source & Strain & $\begin{array}{c}\text { c-type heme } \\
\text { e } 551-540=19.1 \\
\text { (nmoles/mg protein) }\end{array}$ & $\begin{array}{c}\text { b-type heme } \\
\text { e } 561-575=22 \\
\text { (nmoles/mg protein) }\end{array}$ & $\begin{array}{c}\text { a-type heme } \\
\mathrm{e}_{603-630}=11.6 \\
\text { (nmoles/mg protein) }\end{array}$ \\
\hline \multirow[t]{6}{*}{ GLUCOSE } & KF707 W.T. & $1.65 \pm 0.20$ & $0.77 \pm 0.08$ & $0.10 \pm 0.05$ \\
\hline & $\mathrm{KF} \Delta \operatorname{cox} 1-2$ & $1.50 \pm 0.20$ & $0.80 \pm 0.09$ & n.d. \\
\hline & $\mathrm{KF} \Delta \mathrm{cco} 1-2$ & $0.95 \pm 0.15$ & $0.62 \pm 0.07$ & $0.12 \pm 0.05$ \\
\hline & $\mathrm{KF} \Delta \operatorname{cox} 1-2 / \operatorname{cco}^{-1-2}$ & $0.74 \pm 0.10$ & $0.64 \pm 0.07$ & n.d. \\
\hline & $\mathrm{KF} \Delta \mathrm{ClO}$ & $1.42 \pm 0.15$ & $0.84 \pm 0.10$ & $0.12 \pm 0.05$ \\
\hline & $\mathrm{KF} \Delta \operatorname{cox} 1-2 / \mathrm{ClO}$ & $1.09 \pm 0.12$ & $0.61 \pm 0.07$ & n.d. \\
\hline \multirow[t]{6}{*}{ BIPHENYL } & KF707 W.T. & $1.80 \pm 0.20$ & $0.87 \pm 0.10$ & $0.45 \pm 0.03$ \\
\hline & $\mathrm{KF} \Delta \operatorname{cox} 1-2$ & $1.10 \pm 0.09$ & $0.82 \pm 0.10$ & n.d. \\
\hline & $\mathrm{KF} \Delta \mathrm{cco1-2}$ & $0.86 \pm 0.07$ & $0.59 \pm 0.06$ & $0.27 \pm 0.02$ \\
\hline & $\mathrm{KF} \Delta \operatorname{cox} 1-2 / \operatorname{cco}^{-1-2}$ & $0.65 \pm 0.08$ & $0.32 \pm 0.01$ & n.d. \\
\hline & $\mathrm{KF} \Delta \mathrm{ClO}$ & $0.78 \pm 0.09$ & $0.50 \pm 0.03$ & $0.30 \pm 0.02$ \\
\hline & $\mathrm{KF} \Delta \operatorname{cox} 1-2 / \mathrm{ClO}$ & $0.81 \pm 0.07$ & $0.55 \pm 0.03$ & n.d. \\
\hline
\end{tabular}

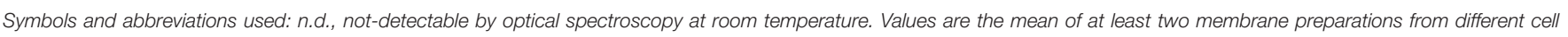
growth cultures for each strain. Mutant phenotype strains abbreviations as in Table 1. See Materials and Methods for experimental details.

TABLE 3 | Respiratory activities in membranes from KF707 W.T. and oxidase mutant cells grown, until the stationary phase (OD 600 nm) 0.7-0.9, in glucose (Gc) as sole carbon source.

\begin{tabular}{|c|c|c|c|c|c|c|c|}
\hline \multirow{2}{*}{$\begin{array}{l}\text { Electron donors } \\
\text { Additions }\end{array}$} & \multicolumn{3}{|c|}{ NADH } & \multicolumn{4}{|c|}{ ASCORBATE } \\
\hline & I & $\mathbf{N}_{3}^{-}$ & $\mathrm{CN}^{-}$ & Cyt C & TMPD & TMPD/N${ }_{3}^{-}$ & $\mathrm{TMPD}^{\mathrm{T}} \mathrm{CN}^{-}$ \\
\hline \multicolumn{8}{|l|}{ STRAINS } \\
\hline KF707 W.T. & $165 \pm 10$ & $72 \pm 3.3$ & $29 \pm 5.0$ & $33 \pm 1.0$ & $157 \pm 20$ & $32 \pm 3.0$ & $7.0 \pm 2.0$ \\
\hline $\mathrm{KF} \Delta \cos 1-2$ & $178 \pm 20$ & $38 \pm 8.0$ & $34 \pm 10$ & $59 \pm 6.0$ & $221 \pm 14$ & $21 \pm 2.5$ & $16 \pm 1.0$ \\
\hline $\mathrm{KF} \Delta \mathrm{cco1-2}$ & $175 \pm 7.0$ & $160 \pm 2.0$ & $125 \pm 1.0$ & $9 \pm 0.5$ & $38 \pm 5.0$ & $32 \pm 3.3$ & $8.0 \pm 1.0$ \\
\hline KF $\Delta \operatorname{cox} 1-2 / c^{-1-2}$ & $174 \pm 15$ & $172 \pm 15$ & $167 \pm 15$ & $1.0 \pm 0.2$ & $11 \pm 2.0$ & $11 \pm 2.0$ & $11 \pm 2.0$ \\
\hline $\mathrm{KF} \Delta \mathrm{ClO}$ & $145 \pm 30$ & $29 \pm 5.0$ & $1.0 \pm 0.2$ & $37 \pm 3.5$ & $208 \pm 31$ & $35 \pm 3.5$ & $10 \pm 0.5$ \\
\hline $\mathrm{KF} \Delta \operatorname{cox} 1-2 / \mathrm{ClO}$ & $145 \pm 5.0$ & $25 \pm 5.0$ & $2.0 \pm 1.0$ & $45 \pm 7.0$ & $163 \pm 12$ & $10 \pm 2.5$ & $10 \pm 2.5$ \\
\hline $\mathrm{KF} \Delta \mathrm{cco} 1$ & $196 \pm 7.0$ & $165 \pm 2.0$ & $110 \pm 3.0$ & $26 \pm 2.5$ & $124 \pm 5.0$ & $12 \pm 3.0$ & $3.0 \pm 1.0$ \\
\hline KF $\Delta \mathrm{cco} 2$ & $220 \pm 10$ & $78 \pm 5.0$ & $51 \pm 5.0$ & $33 \pm 2.5$ & $145 \pm 5.0$ & $37 \pm 3.5$ & $9.0 \pm 2.0$ \\
\hline
\end{tabular}

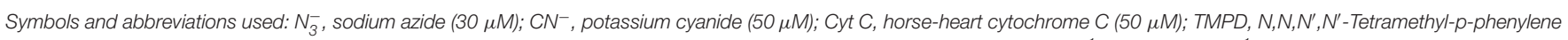

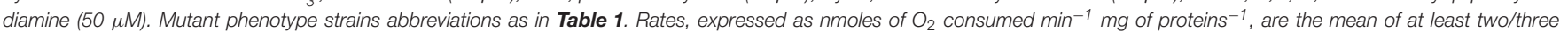
membrane preparations from independent cell cultures.

superfamily (Jünemann, 1997; Borisov et al., 2011) functioning as quinol oxidases.

Type A oxidases encoded by the cox gene cluster are present in a wide range of bacteria and they have a high proton-pumping activity (Brzezinski et al., 2004; Arai et al., 2014). In general, $a a_{3}$ type oxidases show a low affinity for oxygen and usually play a dominant role under high-oxygen conditions in bacteria such as R. sphaeroides and B. subtilis (Gabel and Maier, 1993; Winstedt and von Wachenfeldt, 2000; Arai et al., 2008). If we extend these widely accepted biochemical concepts to $P$. pseudoalcaligenes KF707 redox chain the peculiarity of the membrane terminal oxidase content of this BCPs degrader becomes apparent. In fact, while the sequence analysis allowed classifying Cox in the type A subfamily, the presence in the predicted subunit II (CoxM) of an uncommon extra C-terminal domain carrying two $c$-type hemes binding consensus sequences, suggests that this protein is a $\mathrm{ccaa}_{3}$ type HCO. In agreement to this the C-terminal extension of subunit II (CoxB) from the facultative anaerobic proteobacterium $S$. oneidensis MR-1 was shown to bind two $c$ type hemes (Le Laz et al., 2014). Similarly, this unusual feature was reported in Desulfovibrio spp. (Lobo et al., 2008) and some species of the genus Psychromonas, Colwellia, and Methylosarcina (Le Laz et al., 2014). In Shewanella MR-1, the Ccaa 3 oxidase was expressed at a low level but only under $\mathrm{O}_{2}$-rich growth conditions in LB-medium (Le Laz et al., 2014) while in KF707 the $\mathrm{Ccaa}_{3}$ oxidase is always expressed at a low level regardless the cell growth phase (Figure 2).

As opposed to the CoxM subunit, the CoxB subunit II of T. thermophilus, B.subtilis, and R. marinus has an extra domain carrying only one $c$-type heme (Lauraeus et al., 1991; Mather et al., 1991). This is the case of $\mathrm{caa}_{3}$ type oxidase of KF707 which is highly expressed during the stationary phase in biphenyl 
TABLE 4 | Respiratory activities in membranes from KF707 W.T. and oxidase mutant cells grown, until the stationary phase (OD 600 nm) 0.7-0.9, in biphenyl (Bp) as sole carbon source.

\begin{tabular}{|c|c|c|c|c|c|c|c|}
\hline \multirow{2}{*}{$\begin{array}{l}\text { Electron donors } \\
\text { Additions }\end{array}$} & \multicolumn{3}{|c|}{ NADH } & \multicolumn{4}{|c|}{ ASCORBATE } \\
\hline & I & $\mathbf{N}_{3}^{-}$ & $\mathrm{CN}^{-}$ & CytC & TMPD & $\mathrm{TMPD}^{\mathrm{T}} \mathrm{N}_{3}^{-}$ & $\mathrm{TMPD} \mathrm{CN}^{-}$ \\
\hline \multicolumn{8}{|l|}{ STRAINS } \\
\hline KF707 W.T. & $111 \pm 2.5$ & $64 \pm 9.5$ & $7.0 \pm 0.3$ & $37 \pm 2.0$ & $165 \pm 13$ & $88 \pm 15$ & $7.0 \pm 2.0$ \\
\hline $\mathrm{KF} \Delta \operatorname{cox} 1-2$ & $38 \pm 5.0$ & $9.0 \pm 3.3$ & $3.0 \pm 0.2$ & $17 \pm 3.0$ & $75 \pm 10$ & $5.0 \pm 2.0$ & $3.0 \pm 2.0$ \\
\hline KF $\Delta \mathrm{cco1}^{-2}$ & $96 \pm 9.3$ & $80 \pm 12$ & $29 \pm 0.4$ & $18 \pm 3.0$ & $117 \pm 12$ & $108 \pm 5.0$ & $6.0 \pm 1.7$ \\
\hline $\mathrm{KF} \Delta \operatorname{cox} 1-2 / \operatorname{cco}^{-1-2}$ & $36 \pm 5.0$ & $35 \pm 5.0$ & $35 \pm 5.0$ & $2.0 \pm 1.0$ & $6.0 \pm 2.5$ & $6.0 \pm 2.5$ & $6.0 \pm 2.5$ \\
\hline $\mathrm{KF} \Delta \mathrm{ClO}$ & $83 \pm 4.0$ & $60 \pm 5.0$ & $4.0 \pm 2.0$ & $37 \pm 0.4$ & $174 \pm 1.0$ & $110 \pm 5.0$ & $12 \pm 1.0$ \\
\hline $\mathrm{KF} \Delta \mathrm{cox} 1-2 / \mathrm{ClO}$ & $104 \pm 4.0$ & $15 \pm 2.5$ & $3.5 \pm 1.5$ & $8.3 \pm 3.5$ & $67 \pm 1.0$ & $9.3 \pm 2.0$ & $8.3 \pm 2.0$ \\
\hline $\mathrm{KF} \Delta \mathrm{cco} 1$ & $111 \pm 8.0$ & $97 \pm 7.0$ & $37 \pm 2.0$ & $20 \pm 2.5$ & $201 \pm 18$ & $150 \pm 15$ & $20 \pm 7.0$ \\
\hline $\mathrm{KF} \Delta \mathrm{cco} 2$ & $95 \pm 5.0$ & $46 \pm 5.0$ & $11 \pm 3.0$ & $25 \pm 3.0$ & $200 \pm 20$ & $114 \pm 13$ & $13 \pm 5.0$ \\
\hline
\end{tabular}

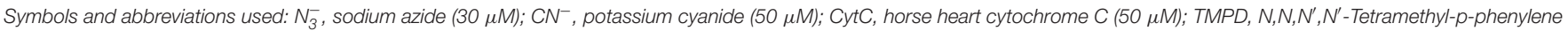

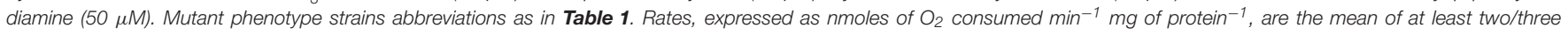
membrane preparations from independent cell cultures.

(Figure 2). In KF707, the presence of c-type hemes in the oxidase catalytic subunits is not only predicted by the amino acid sequences (Supplementary Material-Alignment 1) but it was supported by spectroscopic analysis in which a decrease of the $c$-type heme content in membranes from KF $\Delta$ cox1-2 mutant ( $\mathrm{Caa}_{3} / \mathrm{Ccaa}_{3}$ minus) is seen (Figure S3; Table 2).

Oxidases of $c b b_{3}$ type normally show a very high affinity for oxygen and low proton-translocation efficiency. In bacteria such as $P$. denitrificans, $R$. sphaeroides, and $R$. capsulatus, $c b b_{3}$ oxidases are known to be induced under low oxygen conditions (Preisig et al., 1996a; Mouncey and Kaplan, 1998; Swem and Bauer, 2002). In $P$. aeruginosa $\mathrm{PAO} 1$ one of these $c b b_{3}$ type oxidases, $\mathrm{Cbb}_{3} 1$, is constitutively expressed and plays a primary role in aerobic growth irrespective of oxygen concentration; on the contrary, the expression of $\mathrm{Cbb}_{3} 2$ varies under low oxygen conditions or at the stationary growth phase (Kawakami et al., 2010). The latter regulatory mechanism is also present in KF707 grown on glucose or biphenyl as clearly demonstrated by the constitutive expression of $\mathrm{Cbb}_{3} 1$ while the $\mathrm{Cbb}_{3} 2$ expression varies as a function of the carbon source and growth phase being repressed in the stationary phase of growth in biphenyl (Figure 2).

CIO oxidases are copper-free enzymes that are insensitive to millimolar concentration of cyanide and they function as quinol:oxygen oxidoreductases. Direct determination through the use of Q-electrodes of the Q-pool redox state in membranes from aerobically grown $R$. capsulatus endowed with $\mathrm{Cbb}_{3}$ and CIO oxidases, indicated that the quinol oxidase of CIO type starts being involved in respiration when the Q-pool reduction level reaches $\sim 25 \%$ (Zannoni and Moore, 1990). If this observation is applied to analogous bacterial respiratory chains as those of $R$. sphaeroides, $P$. aeruginosa and KF707 it is apparent that CIO pathways operate as redox valves to prevent the Qpool from exceeding the $25-50 \%$ oxidation-reduction level that is the optimum Q-pool redox state to warrant an efficient energy transduction by the respiratory chain (Klamt et al., 2008). This would explain why cytochrome $\mathrm{Cbb}_{3}$ oxidases are prone to sense environmental redox changes and this is why cio $A B C$ genes coding for $\mathrm{CIO}$, are up-regulated by deletion of the constitutive $\mathrm{Cbb}_{3} 1$ oxidase in $P$. aeruginosa (Comolli and Donohue, 2004). Interestingly, also in P. pseudoalcaligenes KF707 the CIO promoter is up-regulated by deletion of the $\mathrm{Cbb}_{3} 1$ isoform (this work Figure S5) as also confirmed by respiratory activities measured in membranes from $\mathrm{Cbb}_{3} 1$ minus cells (KF $\Delta$ ccol mutant) in which the CIO pathway catalyzes $60 \%$ of respiration as compared to only $17 \%$ of W.T. cells (Table 3). This result confirms that $\mathrm{CIO}$ has a minor role in $\mathrm{KF} 707$ respiration unless the $\mathrm{Cbb}_{3} 1$ isoform is lacking.

\section{The Cyt bc1 Complex and Soluble c-Type Cytochromes}

As shown in the past (Di Tomaso et al., 2002), both NADHand succinic-dehydrogenases channel their electrons into a quinol/cytochrome $c$ oxido-reductase complex (also referred to as complex III or cyt $b c_{1}$ complex) which contains $b$ - and $c$-type heme subunits coded by 1,212 and 780 bp genes, respectively (BAU72674; BAU72675) while the ORF coding for the Rieske domain iron sulfur, $[2 \mathrm{Fe}-\mathrm{S}]$ reductase subunit of the $b c_{1}$ complex, is coded by 591 bp gene (BAU72673). The latter genome annotation confirms early data indicating that the NADHdependent respiration in KF707 is inhibited by the antibiotic antimycin $\mathrm{A}$ which is a specific inhibitor of the cyt $b c_{1}$ complex at the heme $b_{\mathrm{H}}$-Qi interaction site level (Cramer and Knaff, 1990; Di Tomaso et al., 2002).

Analysis of KF707 annotated genome indicated the presence of genes encoding for soluble $c$-type cytochromes, namely: three genes identified as cyt $c_{4}$ (BAU71765, BAU75530, and BAU75507) and two genes identified as cyt $c_{5}$ (BAU77240 and BAU71764) (Supplementary Material-Table S3). Genes BAU71765 and BAU71764 coding for $c_{4}$ and $c_{5}$, respectively, are located in tandem on the same operon (not shown). In the working scheme of Figure 4 (see below) these two soluble $c$-type cytochromes, collectively named as Cyt $c_{\mathrm{s}}$, are supposed to function as electron donors to KF707 terminal oxidases. Because the aim of the present study was to analyse the role of the respiratory oxidases 


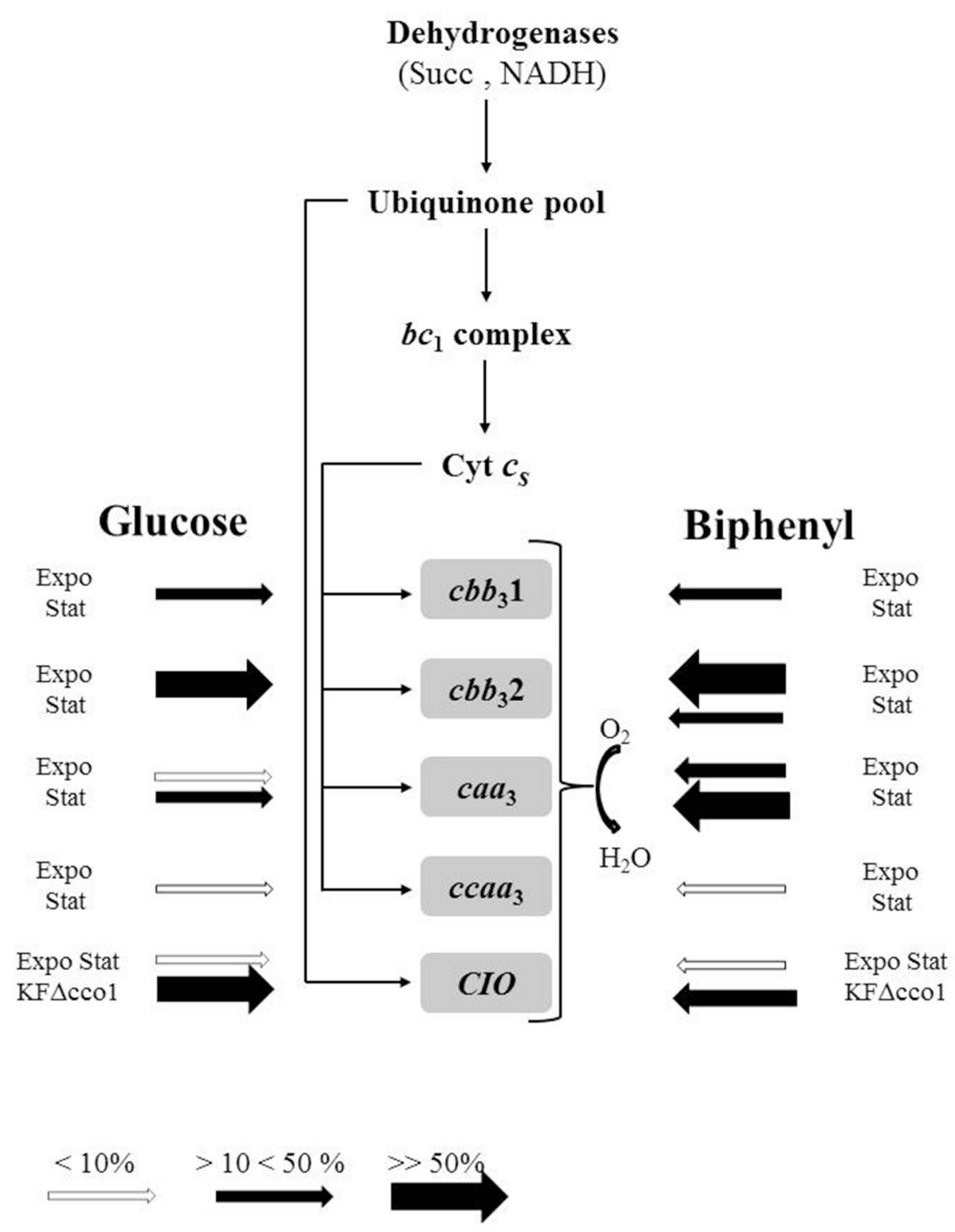

FIGURE 4 | Block scheme illustrating the putative chain of KF707 based on spectroscopic, functional, and genetic analysis (this work and Di Tomaso et al., 2002). Symbols used: Succ, succinate dehydrogenase; NADH, NADH dehydrogenase; Cyt Cs, soluble cytochrome(s) c; bc 1 complex, cytochrome bc 1 complex III; ClO, cyanide insensitive oxidase (bd type) (encoded by cioABC); caa3, cytochrome $c$ oxidase (encoded by coxI-II-III cluster); ccaa 3 , cytochrome $c$ oxidase (encoded by coxMNOP); $c b b_{3} 1$, cytochrome $c$ oxidase (encoded by ccoN1O1Q1P1); cbb32, cytochrome $c$ oxidase (encoded by ccoN2O2Q2P2); KF $\Delta c c 01$, Cbb 1 minus mutant. The size and color of the arrows symbolize the \% level of expression of terminal oxidases under the tested growth conditions, namely: cells grown in glucose or biphenyl and harvested during their exponential (Expo) or stationary (Stat) phase of growth. The actual expression values are those of Figure $\mathbf{2}$.

no further effort was made to understand the specific function of the soluble $c$-type hemes in KF707.

\section{Effect of the Carbon Source on the Arrangement of KF707 Respiratory Chain} KF707 cells grown in LB-medium do not contain detectable amounts of $a a_{3}$-type hemes regardless the phase of growth (Di Tomaso et al., 2002). Conversely we show here that spectroscopic significant amounts of $c(c) a a_{3}$ type hemes are present in KF707 cells grown in minimal-salt media supplemented with biphenyl as sole carbon source (Table 2). Further, results of Figure 2 and Table 4 indicate that both cox123 gene expression and catalytic activity ( $\mathrm{Caa}_{3}$ oxidase) are greatly enhanced in biphenyl grown cells. This effect was paralleled by a drastic decrease (7fold) in the expression of the $\mathrm{Cbb}_{3} 2$ oxidase which was not compensated by a parallel increase of the CIO quinol oxidase activity while the $\mathrm{Cbb}_{3} 1$ oxidase was constitutively expressed (Figure 2 and Table 4). These results are of particular interest 
because they outline a new bioenergetics scenario in which two respiratory oxidases of $P$. pseudoalcaligenes KF707 are modulated by biphenyl that is the metabolite which allows the co-metabolic degradation of PCBs by KF707. In this respect, while the response of the central carbon catabolism to environmental signals such as oxygen and/or nutritional compounds has been analyzed in some detail (Arras et al., 1998; Krooneman et al., 1998), the modulation of the oxidative ETC by the carbon source used for growth is far less documented (Dominguez-Cuevas et al., 2006; Arai, 2011; Arai et al., 2014). It is known that oxidases of $a a_{3}$ type are affected by carbon starvation which was shown to induce a cox gene up-regulation in $P$. aeruginosa. This regulatory mechanism is linked to a cell response toward a more efficient energy-transducing $a a_{3}$ oxidase under low nutrient conditions (Kawakami et al., 2010; Arai, 2011). As far as concern the role of $c(c) a a_{3}$ type oxidases in KF707 grown in biphenyl, the growth results can be summarized as following (Figure 3B): (1) the growth rate of the $c(c) a a_{3}$ double mutant $(g=94 \pm 6.1 \mathrm{~min})$ is similar to that of W.T. $(g=97 \pm 8.5 \mathrm{~min})$; (2) the lack of both $\mathrm{Cbb}_{3} 1$ and $\mathrm{Cbb}_{3} 2$ oxidases slows down KF707 cell growth ( $g=140 \pm 21 \mathrm{~min}$ ); (3) the $\mathrm{C}(\mathrm{c}) \mathrm{aa}_{3} / \mathrm{CIO}$ minus phenotype is only slightly affected in its growth rate $(g=117 \pm 1.5 \mathrm{~min})$ as compared to W.T.; (4) the $\mathrm{Cbb}_{3} 1$ minus phenotype is impaired in its growth rate $(g=151 \pm 1.7 \mathrm{~min})$ in spite of $\mathrm{Caa}_{3}$ overexpression; (5) growth of the quadruple cytochrome oxidase mutant $\mathrm{Cbb}_{3} 1-2 / \mathrm{C}(\mathrm{c}) \mathrm{aa}_{3}$, although impaired, is still supported by the oxidase activity of $\mathrm{CIO}$ which is up-regulated $(g=146 \pm$ 16 min), and finally (6) all attempts to obtain a KF707 mutant carrying a $\mathrm{Cbb}_{3} 1-2 / \mathrm{CIO}$ minus phenotype were unsuccessful. Overall these data suggest that the C(c)aa $\mathrm{aa}_{3}$ oxidases of KF707 are unable to sustain aerobic growth when they are present as the only terminal oxidases as it was noticed in Shewanella MR-1 whose genome is predicted to encode for a terminal Cox oxidase annotated as $\mathrm{Ccaa}_{3}$ oxidase (Le Laz et al., 2014). In the past it was shown that a mutant of $P$. aeruginosa PAO1 that lacked four terminal oxidase gene clusters except for the cox genes (strain QXAa) was unable to grow aerobically in LB (Arai et al., 2014). More recently, a suppressor mutant of QXAa (QXAaS2) that grew aerobically using only the cox genes for $\mathrm{caa}_{3}$ (formerly reported as $a a_{3}$ ) was described, in which a mutation in the

\section{REFERENCES}

Abramowicz, D. A. (1990). Aerobic and anaerobic biodegradation of PCBs: a review. Crit. Rev. Biotechnol. 10, 241-251. doi: 10.3109/073885590090 38210

Altschul, S. F., Gish, W., Miller, W., Myers, E. W., and Lipman, D. J. (1990). Basic local alignment search tool. J. Mol. Biol. 215, 403-410. doi: 10.1016/S0022-2836(05)80360-2

Alvarez-Ortega, C., and Harwood, C. S. (2007). Responses of Pseudomonas aeruginosa to low oxygen indicate that growth in the cystic fibrosis lung is by aerobic respiration. Mol. Microbiol. 65, 153-165. doi: 10.1111/j.1365-2958.2007.05772.x

Arai, H. (2011). Regulation and function of versatile aerobic and anaerobic respiratory metabolism in Pseudomonas aeruginosa. Front. Microbiol. 2:103. doi: $10.3389 /$ fmicb. 2011.00103

Arai, H., Kawakami, T., Osamura, T., Hirai, T., Sakai, Y., and Ishii, M. (2014). Enzymatic characterization and in vivo function of five two-component regulator RoxSR was necessary for the aerobic growth of PAO1 in LB (Osamura et al., 2017). Apparently, the expression and function of bacterial cyt $c$ oxidases of $C(c) a a_{3}$ type under variable growth conditions is far from being fully examined (Brzezinski et al., 2004; Arai, 2011; Osamura et al., 2017).

The scheme in Figure 4 represents the state of knowledge on the functional arrangement of the ETC in the PCBs-degrader P. pseudoalcaligenes KF707. A study is currently underway to understand the ETC's regulation mechanism as a function of the two carbon sources here used for cell growth, glucose, and biphenyl, along with the search for growth conditions under which the $\mathrm{Ccaa}_{3}$ oxidases of KF707 is significantly expressed.

\section{AUTHOR CONTRIBUTIONS}

SF and FS: conceived, designed, and performed part of the experiments, assisted in design of the study and co-wrote the Manuscritpt. MC: assisted in design of the study and co-wrote the manuscript. FC and RT assisted in design of the study. DZ: conceived, directed, supervised, and co-wrote the Manuscript.

\section{ACKNOWLEDGMENTS}

We wish to thank the University of Bologna for supporting this work (RFO grants 2013-16) and the "Vasco e GC Rossi Foundation" (Microbial Biofilm grant 2012-2015). FS was supported by a PhD fellowship given by the University of Bologna. The contribution of RT was supported by NSERC grant (RGPIN/219895-2010). We are also indebted to Tania TriscariBarberi, Roberta Rosa Susca, Domenico Simone, Marcella Attimonelli for their early contribution in the annotation and sequencing of $P$. pseudoalcaligenes KF707 genome (TriscariBarberi et al., 2012).

\section{SUPPLEMENTARY MATERIAL}

The Supplementary Material for this article can be found online at: http://journal.frontiersin.org/article/10.3389/fmicb. 2017.01223/full\#supplementary-material terminal oxidases in Pseudomonas aeruginosa. J. Bacteriol. 196, 4206-4215. doi: 10.1128/JB.02176-14

Arai, H., Roh, J. H., and Kaplan, S. (2008). Transcriptome dynamics during the transition from anaerobic photosynthesis to aerobic respiration in Rhodobacter sphaeroides 2.4.1. J. Bacteriol. 190, 286-299. doi: 10.1128/JB.01375-07

Arras, T., Schirawski, J., and Unden, G. (1998). Availability of $\mathrm{O}_{2}$ as a substrate in the cytoplasm of bacteria under aerobic and microaerobic conditions. $J$. Bacteriol. 180, 2133-2136.

Borisov, V. B., Gennis, R. B., Hemp, J., and Verkhosky, M. I. (2011). The cytochrome bd respiratory oxygen reductases. Biochim. Biophys. Acta 1807, 1398-1413. doi: 10.1016/j.bbabio.2011.06.016

Bott, M., Preisig, O., and Hennecke, H. (1992). Genes for a second terminal oxidase in Bradyrhizobium japonicum. Arch. Microbiol. 158, 335-343. doi: 10.1007/BF00245362

Boyer, H. W., and Roulland-Dussoix, D. (1969). A complementation analysis of the restriction and modification of DNA in Escherichia coli. 41, 459-472. doi: 10.1016/0022-2836(69)90288-5 
Brzezinski, P., Larsson, G., and Adelroth, P. (2004). "Functional aspects of hemecopper terminal oxidases," in Advances in Photosynthesis and Respiration, Vol. 15: Respiration in Archaea and Bacteria. Diversity of Prokaryotic Electron Transport Carriers, ed D. Zannoni (Dordrecht: Kluwer Academic Publishers), 129-153.

Bueno, E., Mesa, S., Bedmar, E. J., Richardson, D., and Delgado, M. J. (2012). Bacterial adaptation of respiration from oxic to microoxic and anoxic conditions: redox control. Antioxid. Redox Signal. 16, 819-852. doi: 10.1089/ars.2011.4051

Chang, H.-Y., Ahn, Y., Pace, L. A., Lin, M. T., Lin, Y.-H., and Gennis, R. B. (2010). The diheme cytochrome $c_{4}$ from Vibrio cholerae is a natural electron donor to the respiratory $c b b_{3}$ oxygen reductase. Biochemistry $49,7494-7503$. doi: $10.1021 /$ bi1004574

Choi, K. H., Gaynor, J. B., White, K. G., Lopez, C., Bosio, C. M., KarkhoffSchweizer, R. R., et al. (2005). A Tn7-based broad-range bacterial cloning and expression system. Nat. Methods 6, 443-448. doi: 10.1038/nmeth765

Choi, K. H., and Schweizer, H. P. (2006). mini-Tn7 insertion in bacteria with single att $\mathrm{Tn} 7$ sites: example Pseudomonas aeruginosa. Nat. Protoc. 1, 153-161. doi: $10.1038 /$ nprot.2006.24

Comolli, J. C., and Donohue, T. J. (2002). Pseudomonas aeruginosa RoxR, a response regulator related to Rhodobacter sphaeroides PrrA, activates the expression of the cyanide-insensitive terminal oxidase. Mol. Microbiol. 45, 755-768. doi: 10.1046/j.1365-2958.2002.03046.x

Comolli, J. C., and Donohue, T. J. (2004). Differences in two Pseudomonas aeruginosa $\mathrm{cbb}_{3}$ cytochrome oxidases. Mol. Microbiol. 51, 1193-1203. doi: 10.1046/j.1365-2958.2003.03904.x

Cramer, W. A., and Knaff, D. B. (1990). Energy Transduction in Biological Membranes. New York, NY: Springer-Verlag.

Cunningham, L., Pitt, M., and Williams, H. D. (1997). The cioAB genes from Pseudomonas aeruginosa code for a novel $\mathrm{CN}^{-}$insensitive terminal oxidase related to the cytochrome $b d$ quinol oxidases. Mol. Microbiol. 24, 579-591. doi: 10.1046/j.1365-2958.1997.3561728.x

D'mello, R., Hill, S., and Poole, R. K. (1996). The cytochrome $b d$ quinol oxidase in Escherichia coli has an extremely high oxygen affinity and two-oxygen binding haems: implications for regulation of activity in vivo by oxygen inhibition. Microbiology 142, 755-763.

Daldal, F., Mandaci, S., Winterstein, C., Myllykallio, H., Duyck, K., and Zannoni, D. (2001). Mobile cytochrome $c_{2}$ and membrane-anchored cytochrome cy are both efficient electron donors to the $\mathrm{cbb}_{3}$ - and aa 3 -type cytochrome $\mathrm{c}$ oxidases during respiratory growth of Rhodobacter sphaeroides. J. Bacteriol. 183, 2013-2024. doi: 10.1128/JB.183.6.2013-2024.2001

Di Tomaso, G., Fedi, S., Carnevali, M., Manegatti, M., Taddei, C., and Zannoni, D. (2002). The membrane-bound respiratory chain of Pseudomonas pseudoalcaligenes KF707 cells grown in the presence or absence of potassium tellurite. Microbiology 148, 1699-1708. doi: 10.1099/00221287-148-6-1699

Dominguez-Cuevas, P., Gonzales-Pastor, J. E., Marques, S., Ramos, J. L., and de Lorenzo, V. (2006). Transcriptional tredoff between metabolic and stressresponse programs in Pseudomonas putida KT2440 cells exposed to toluene. J. Biol. Chem. 281, 11981-11991. doi: 10.1074/jbc.M509848200

Fedi, S., Carnevali, M., Fava, F., Andracchio, A., Zappoli, S., and Zannoni, D. (2001). Polychlorinated biphenyl degradation activities and hybridization analyses of fifteen aerobic strains isolated from a PCB-contaminated site. Res. Microbiol. 152, 583-592. doi: 10.1016/S0923-2508(01)01233-5

Figurski, D. H., and Helinski, D. R. (1979). Replication of an origin-containing derivative of plasmid RK2 dependent on a plasmid function provided in trans. Proc Natl. Acad. Sci. U.S.A. 76, 1648-1652. doi: 10.1073/pnas.76.4. 1648

Fujihara, H., Yoshida, H., Matsunaga, T., Goto, M., and Furukawa, K. (2006). Cross-regulation of biphenyl- and salicylate-catabolic genes by two regulatory systems in Pseudomonas pseudoalcaligenes KF707. J. Bacteriol. 188, 4690-4697. doi: 10.1128/JB.00329-06

Furukawa, K., Hirose, J., Suyama, A., Zaiki, T., and Hayashida, S. (1993). Gene components responsible for discrete substrate specificity in the metabolism of biphenyl (bph) and toluene (tod) operons. J. Bacteriol. 175, 5224-5232. doi: $10.1128 /$ jb.175.16.5224-5232.1993

Furukawa, K., and Miyazaki, T. (1986). Cloning of a gene cluster encoding biphenyl and chlorobiphenyl degradation in Pseudomonas pseudoalcaligenes KF707. J. Bacteriol. 166, 392-398. doi: 10.1128/jb.166.2.392-398.1986
Gabel, C., and Maier, R. J. (1993). Oxygen-dependent transcriptional regulation of cytochrome $a a_{3}$ in Bradyrhizobium japonicum. J. Bacteriol. 175, 128-132. doi: $10.1128 /$ jb.175.1.128-132.1993

Hanahan, D. (1983). Studies on transformation of Escherichia coli with plasmids. J. Mol. Biol. 166, 557-580. doi: 10.1016/S0022-2836(83)80284-8

Hoang, T. T., Karkhoff-Schweizer, R. R., Kutchma, A. J., and Schweizer, H. P. (1998). A broad-host-range Flp-FRT recombination system for sitespecific excision of chromosomally-located DNA sequences: application for isolation of unmarked Pseudomonas aeruginosa mutants. Gene 212, 77-86. doi: 10.1016/S0378-1119(98)00130-9

Izumi, K., Aramaki, M., Kimura, T., Naito, Y., Udaka, T., Uchikawa, M., et al. (2007). Identification of a prosencephalic-specific enhancer of SALL1: comparative genomic approach using the chick embryo. Pediatr. Res. 61, 660-665. doi: 10.1203/pdr.0b013e318053423a

Jünemann, S. (1997). Cytochrome $b d$ terminal oxidase. Biochim. Biophys. Acta 1321, 107-127. doi: 10.1016/S0005-2728(97)00046-7

Kawakami, T., Kuroki, M., Ishii, M., Igarashi, Y., and Arai, H. (2010). Differential expression of multiple terminal oxidases for aerobic respiration in Pseudomonas aeruginosa. Environ. Microbiol. 12, 1399-1412. doi: 10.1111/j.1462-2920.2009.02109.x

Kishikawa, J.-I, Kabashima, Y., Kurokawa, T., and Sakamato, J. (2010). The cytochrome bcc-aa3 type respiratory chain of Rhodococcus rhodochrous. J. Biosci. Bioeng. 110, 42-47. doi: 10.1016/j.jbiosc.2009.12.006

Klamt, S., Grammel, H., Starube, R., Ghosh, R., and Gilles, E. D. (2008). Modelling the electron transport chain of purple non-sulfur bacteria. Mol. Syst. Biol. 4:156. doi: $10.1038 / \mathrm{msb} 4100191$

Koch, H. G., Winterstein, C., Saribas, A. S., Alben, J. O., and Daldal, F. (2000). Roles of the $c c o$ GHIS gene products in the biogenesis of the $c b b_{3}$-type cytochrome $c$ oxidase. J. Mol. Biol. 297, 49-65. doi: 10.1006/jmbi.2000.3555

Krooneman, J., Moore, E. R. B., van Velzen, J. C. L., Prins, R. A., Forney, L. J., and Gottschal, J. C. (1998). Competition for oxygen and 3-chlorobenzoate between two aerobic bacteria using different degradation pathways. FEMS Microbiol. Ecol. 26, 171-179. doi: 10.1111/j.1574-6941.1998.tb00503.x

Lauraeus, M., Haltia, T., Saraste, M., and Wikstrom, M. (1991). Bacillus subtilis expresses two kinds of haem-A-containing terminal oxidases. Eur. J. Biochem. 197, 699-705. doi: 10.1111/j.1432-1033.1991.tb15961.x

Le Laz, S., Kpebe, A., Bauzan, M., Lignon, S., Rousset, M., and Brugna, M. (2014). A biochemical approach to study the role of the terminal oxidases in aerobic respiration of Shewanella oneidensis MR-1. PLoS ONE 9:e86343. doi: 10.1371/journal.pone. 0086343

Lobo, S. A., Almeida, C. C., Carita, J. N., Teixeira, M., and Saraiva, L. M. (2008). The haem-copper oxygen reductase of Desulfovibrio vulgaris contains a dihaem cytochrome $c$ in subunit II. Biochim. Biophys. Acta 1777, 1528-1534. doi: 10.1016/j.bbabio.2008.09.007

Lowry, O. H., Rosebrough, N. J., Farr, A. L., and Randall, R. J. (1951). Protein measurement with Folin phenol reagent. J. Biol. Chem. 193, 265-275.

Lyons, J. A., Aragao, D., Slattery, O., Pisliakov, A. V., Soulimane, T., and Caffrey, M. (2012). Structural insights into electron transfer in $\mathrm{caa}_{3}$-type cytochrome oxidase. Nature 487, 514-520. doi: 10.1038/nature 11182

Marrs, B. L., and Gest, H. (1973). Genetic mutations affecting the respiratory electron transport system of the photosynthetic bacterium Rhodopseudomonas capsulate. J. Bacteriol. 114, 1045-1051.

Maseda, H., Sawada, I., Saito, K., Uchiyama, H., Nakae, T., and Nomura, N. (2004). Enhancement of the mexAB-oprM efflux pump expression by a quorumsensing autoinducer and its cancellation by a regulator, MexT, of the mexEFoprN efflux pump operon in Pseudomonas aeruginosa. Antimicrob. Agents Chemiother. 48, 1320-1328. doi: 10.1128/AAC.48.4.1320-1328.2004

Mather, M. W., Springer, P., and Fee, J. A. (1991). Cytochrome oxidase genes from Thermus thermophilus. Nucleotide sequence and analysis of the deduced primary structure of subunit IIc of cyt caa 3 . J. Biol. Chem. 266, 5025-5035.

Matsushita, K., Yamada, M., Shinagawa, E., Adachi, O., and Ameyama, M. (1983). Membrane-bound respiratory chain of Pseudomonas aeruginosa grown aerobically. A KCN-insensitive alternate oxidase chain and its energetics. $J$. Biochem. 93, 1137-1144. doi: 10.1093/oxfordjournals.jbchem.a134239

Mouncey, N. J., and Kaplan, S. (1998). Oxygen regulation of the ccoN gene encoding a component of the $c b b_{3}$ oxidase of Rhodobacter sphaeroides 2.4.1.T: involvement of the FnrL protein. J. Bacteriol. 180, 2228-2231. 
Nikel, P. I., and Chavarria, M. (2015). "Quantitative physiology approaches to understand and optimize reducing power availability in environmental bacteria," in Hydrocarbon and Lipid Microbiology Protocols, eds T. J. McGenity, K. N. Timmis, and B. Nogales-Fernandez (Heidelberg: Humana Press), 1-32.

Nikel, P. I., Perez-Pantoja, D., and de Lorenzo, V. (2016). Pyridine nucleotide transhydrogenases enable redox balance of Pseudomonas putida during biodegradation of aromatic compounds. Environ. Microbiol. 18, 3565-3582. doi: 10.1111/1462-2920.13434

Osamura, T., Kawakami, T., Kido, R., Ishii, M., and Arai, K. (2017). Specific expression and function of the A-type cytochrome oxidase under starvation conditions in Pseudomonas aeruginosa. PLoS ONE 12:e177957. doi: 10.1371/journal.pone.0177957

Pitcher, R. S., and Watmough, N. J. (2004). The Bacterial cytochrome $c b b_{3}$ oxidases. Biochim. Biophys. Acta 1655, 388-399. doi: 10.1016/j.bbabio.2003.09.017

Poole, R. K., and Cook, G. M. (2000). Redundancy of aerobic respiratory chains in bacteria? Routes, reasons and regulation. Adv. Microb. Physiol. 43, 165-224. doi: 10.1016/S0065-2911(00)43005-5

Preisig, O., Zufferey, R., and Hennecke, H. (1996a). The Bradyrhizobium japonicum fixGHIS genes are required for the formation of the highaffinity cbb3-type cytochrome oxidase. Arch. Microbiol. 165, 297-305. doi: $10.1007 / \mathrm{s} 002030050330$

Preisig, O., Zufferey, R., Thöny-Meyer, L., Appleby, C. A., and Hennecke, H. (1996b). A high-affinity $c b b_{3}$-type cytochrome oxidase terminates the symbiosis-specific respiratory chain of Bradyrhizobium japonicum. J. Bacteriol. 178, 1532-1538. doi: 10.1128/jb.178.6.1532-1538.1996

Rojo, F. (2010). Carbon catabolite repression in Pseudomonas: optimizing metabolic versatility and interactions with the environment. FEMS Microbiol. Rev. 34, 658-684. doi: 10.1111/j.1574-6976.2010.00218.x

Sambrook, K., Fritsch, E. F., and Maniatis, T. (1989). Molecular Cloning: A Laboratory Manual, 2nd Edn. Cold Spring Harbor, NY: Cold Spring Harbor Laboratory.

Sevilla, E., Alvarez-Ortega, C., Krell, T., and Rojo, F. (2013). The Pseudomonas putida HskA hybrid sensor kinase responds to redox singals and contributes to the adaptation of the electron transport composition in response to oxygen availability. Environ. Microbiol. Rep. 5, 825-834. doi: 10.1111/1758-2229.12083

Shimizu, K. (2014). Regulation systems of bacteria such as E. coli in response to nutrient limitation and environmental stresses. Metabolites 4, 1-35. doi: 10.3390/metabo4010001

Siletsky, S. A., Rapport, F., Poole, R. K., and Borisov, V. B. (2016). Evidence for fast electron transfer between the high-spin haems in cytochrome $b d$-I from Escherichia coli. PLoS ONE 11:e0155186. doi: 10.1371/journal.pone.0155186

Sousa, F. L., Alves, R. J., Ribeiro, M. A., Pereira-Leal, J. B., Teixeira, M., and Pereira, M. M. (2012). The superfamily of heme-copper oxygen reductases: types and evolutionary considerations. Biochim. Biophys. Acta 1817, 629-637. doi: 10.1016/j.bbabio.2011.09.020

Stover, C. K., Pham, X. Q., Erwin, A. L., Mizoguchi, S. D., Warrener, P., Hickey, M. J., et al. (2000). Complete genome sequence of Pseudomonas aeruginosa PAO1, an opportunistic pathogen. Nature 406, 959-964. doi: 10.1038/35023079

Swem, D. L., and Bauer, C. E. (2002). Coordination of ubiquinol oxidase and cytochrome $c b b_{3}$ oxidase expression by multiple regulators in Rhodobacter capsulatus. J. Bacteriol. 184, 2815-2820. doi: 10.1128/JB.184.10.2815-28 20.2002

Taira, K., Hirose, J., Hayashida, S., and Furukawa, K. (1992). Analysis of $b p h$ operon from the polychlorinated biphenyl-degrading strain of Pseudomonas pseudoalcaligenes KF707. J. Biol. Chem. 267, 4844-4853.

Thompson, J. D., Higgins, D. G., and Gibson, T. J. (1994). CLUSTAL W: improving the sensitivity of progressive multiple sequence alignment through sequence weighting, position-specific gap penalties and weight matrix choice. Nucleic Acids Res. 22, 4673-4680. doi: 10.1093/nar/22.22.4673

Tremaroli, V., Fedi, S., Tamburini, S., Viti, C., Tatti, E., Ceri, H., et al. (2011). A histidine-kinase cheA gene of Pseudomonas pseudoalcaligens KF707 not only has a key role in chemotaxis but also affects biofilm formation and cell metabolism. Biofouling 27, 33-46. doi: 10.1080/08927014.2010.537099

Tremaroli, V., Fedi, S., Turner, R. J., Ceri, H., and Zannoni, D. (2008). Pseudomonas pseudoalcaligenes KF707 upon biofilm formation on a polystyrene surface acquire a strong antibiotic resistance with minor changes in their tolerance to metal cations and metalloid oxyanions. Arch. Microbiol. 190, 29-39. doi: 10.1007/s00203-008-0360-z

Tremaroli, V., Fedi, S., and Zannoni, D. (2007). Evidence for a tellurite dependent generation of reactive oxygen species and absence of a tellurite mediated adaptive response to oxidative stress in cells of Pseudomonas pseudoalcaligenes KF707. Arch. Microbiol. 187, 127-135. doi: 10.1007/s00203-006-0179-4

Tremaroli, V., Vacchi-Suzzi, C., Fedi, S., Ceri, H., Zannoni, D., and Turner, R. J. (2010). Tolerance of Pseudomonas pseudoalcaligenes KF707 to metals, polychlorobiphenyls and chlorobenzoates: effects on chemotaxis-, biofilm- and planktonic-grown cells. FEMS. Microbiol. Ecol. 74, 291-301. doi: 10.1111/j.1574-6941.2010.00965.x

Triscari-Barberi, T., Simone, D., Calabrese, F. M., Attimonelli, M., Hahn, K. R., Amoako, K. K., et al. (2012). Genome sequence of the polychlorinated-biphenyl degrader Pseudomonas pseudoalcaligenes KF707. J. Bacteriol. 194, 4426-4427. doi: 10.1128/JB.00722-12

Winstedt, L., and von Wachenfeldt, C. (2000). Terminal oxidases of Bacillus subtilis strain 168: one quinol oxidase, cytochrome $a a_{3}$ or cytochrome $b d$, is required for aerobic growth. J. Bacteriol. 182, 6557-6564. doi: 10.1128/JB.182.23.6557-6564.2000

Zannoni, D., and Moore, A. L. (1990). Measurement of the redox state of the ubiquinone pool in Rhodobacter capsulatus membrane fragments. FEBS Lett. 271, 123-127. doi: 10.1016/0014-5793(90)80387-X

Conflict of Interest Statement: The authors declare that the research was conducted in the absence of any commercial or financial relationships that could be construed as a potential conflict of interest.

Copyright (C) 2017 Sandri, Fedi, Cappelletti, Calabrese, Turner and Zannoni. This is an open-access article distributed under the terms of the Creative Commons Attribution License (CC BY). The use, distribution or reproduction in other forums is permitted, provided the original author(s) or licensor are credited and that the original publication in this journal is cited, in accordance with accepted academic practice. No use, distribution or reproduction is permitted which does not comply with these terms. 